\title{
Investigating hookworm genomes by comparative analysis of two
} Ancylostoma species

\author{
Makedonka Mitreva*†1, James P McCarter ${ }^{\dagger 1,2}$, Prema Arasu ${ }^{3}$, John Hawdon ${ }^{4}$, \\ John Martin ${ }^{1}$, Mike Dante ${ }^{1}$, Todd Wylie ${ }^{1}$, Jian $\mathrm{Xu}^{1}$, Jason E Stajich ${ }^{5}$, \\ Wadim Kapulkin ${ }^{6,7}$, Sandra W Clifton ${ }^{1}$, Robert H Waterston ${ }^{1,8}$ and \\ Richard K Wilson ${ }^{1}$
}

Address: ${ }^{1}$ Genome Sequencing Center, Department of Genetics, Washington University School of Medicine, St. Louis, MO 63108, USA, ${ }^{2}$ Divergence Inc., St. Louis, MO 63141, USA, ${ }^{3}$ College of Veterinary Medicine, Department of Molecular Biomedical Sciences, North Carolina State University, Raleigh, NC 27606, USA, ${ }^{4}$ Department of Microbiology and Tropical Medicine, George Washington University Medical Center, Washington, DC 20037, USA, ${ }^{5}$ Department of Molecular Genetics and Microbiology, Duke University, Durham, NC 27710, USA, ${ }^{6}$ Department of Infectious Diseases, Microbiology and Parasitology, Faculty of Veterinary Medicine, Warsaw Agricultural University, Warszawa, Poland, ${ }^{7}$ School of Biology, University of Leeds, LEEDS LS2 9JT, UK and ${ }^{8}$ Department of Genome Sciences, University of Washington, Seattle, WA 98195, USA

Email: Makedonka Mitreva* - mmitreva@watson.wustl.edu; James P McCarter - jmccarte@watson.wustl.edu;

Prema Arasu - prema_arasu@ncsu.edu; John Hawdon - mtmjmh@gwumc.edu; John Martin - jmartin@watson.wustl.edu; Mike Dante - mdante@watson.wustl.edu; Todd Wylie - twylie@watson.wustl.edu; Jian Xu - jxu@watson.wustl.edu;

Jason E Stajich - jason@cgt.duhs.duke.edu; Wadim Kapulkin - bgywjk@leeds.ac.uk; Sandra W Clifton - sclifton@watson.wustl.edu; Robert H Waterston - waterston@gs.washington.edu; Richard K Wilson - rwilson@watson.wustl.edu

* Corresponding author †Equal contributors

Published: 26 April 2005

BMC Genomics 2005, 6:58 doi:10.1/86/147|-2164-6-58
Received: I4 December 2004

Accepted: 26 April 2005

This article is available from: http://www.biomedcentral.com/147I-2/64/6/58

(c) 2005 Mitreva et al; licensee BioMed Central Ltd.

This is an Open Access article distributed under the terms of the Creative Commons Attribution License (http://creativecommons.org/licenses/by/2.0), which permits unrestricted use, distribution, and reproduction in any medium, provided the original work is properly cited.

\begin{abstract}
Background: Hookworms, infecting over one billion people, are the mostly closely related major human parasites to the model nematode Caenorhabditis elegans. Applying genomics techniques to these species, we analyzed 3,840 and 3,149 genes from Ancylostoma caninum and A. ceylanicum.
\end{abstract}

Results: Transcripts originated from libraries representing infective L3 larva, stimulated L3, arrested $\mathrm{L} 3$, and adults. Most genes are represented in single stages including abundant transcripts like hsp-20 in infective L3 and vit-3 in adults. Over $80 \%$ of the genes have homologs in C. elegans, and nearly $30 \%$ of these were with observable RNA interference phenotypes. Homologies were identified to nematode-specific and clade $V$ specific gene families. To study the evolution of hookworm genes, 574 A. caninum / A. ceylanicum orthologs were identified, all of which were found to be under purifying selection with distribution ratios of nonsynonymous to synonymous amino acid substitutions similar to that reported for $C$. elegans / C. briggsae orthologs. The phylogenetic distance between $A$. caninum and A. ceylanicum is almost identical to that for C. elegans / C. briggsae.

Conclusion: The genes discovered should substantially accelerate research toward better understanding of the parasites' basic biology as well as new therapies including vaccines and novel anthelmintics. 


\section{Background}

Comparative sequence analysis is an approach proven to aid in recognition of genes and defining of their function, especially when comparing genomes of close evolutionary distance. In addition, when partial genomes are placed in a context of a well-studied and fully sequenced model organism they can greatly facilitate the understanding of the less studied organisms' biology.

Hookworms are blood-feeding nematodes that infect one billion people causing iron deficiency anemia and retarded physical and cognitive development in children [1]. The two major species infecting humans are Necator americanus and Ancylostoma duodenale. The closely related hookworm species of canids, Ancylostoma caninum, and canines and felines, A. ceylanicum, are minor parasites of humans, but are important as laboratory models for hookworm infection and disease. Other hookworms infect raccoons, sheep, seals and a variety of other mammals [2]

Adult (Ad) hookworms inhabit the small intestine and produce eggs that pass in the feces and hatch in the soil. The first stage larva (L1) feeds on bacteria and molts twice to form the non-feeding, infective third stage (iL3). iL3 enters the host by penetrating the skin, or orally in the case of Ancylostoma species, molts twice, and matures to Ad in the small intestine. A. duodenale and A. caninum L3s can also infect a host, temporarily abort maturation and enter an arrested state (hypobiosis) within the host's somatic tissues [3], reactivating in response to host physiological changes such as pregnancy [4].

Current hookworm control strategies are limited to deworming of infected people using anthelmintic drugs. However, rapid re-infection in endemic areas and the lack of sterile immunity necessitates repeated treatments and can in turn result in resistance. Additionally, tissuearrested stages are relatively resilient to the effects of anthelmintics [5]. The Human Hookworm Vaccine Initiative is beginning clinical trials of a larval hookworm antigen, ASP-2, from N. americanus, as a vaccine antigen [6]. There is a critical need for further research to identify new vaccine and drug targets as well as to better understand hookworm biology. Lack of sequence information has been a major hindrance to hookworm molecular studies. High throughput sequencing of expressed sequence tags (ESTs; sequences derived from randomly selected cDNA clones) has proven a cost-effective tool for discovering genes [7]. Because the hookworm superfamily (Ancylostomatoidea) falls within nematode Clade V [8,9], which also contains the well-studied model nematode Caenorhabditis elegans [10], predictions may be made and tested based on their close relatedness. Previous genomebased characterization of hookworms has been limited to sampling of few hundred ESTs [11] and molecular studies of individual genes of interest (eg. [12]; reviewed in [13]). EST approaches have also been initiated for other Strongylid parasites including Haemonchus contortus [14,15] and Nippostrongylus brasiliensis [16].

In this report we describe the comparative analyses of almost 20,000 ESTs from 7 different cDNA libraries representing pre-parasitic and parasitic larval through adult stages of the hookworms A. caninum and A. ceylanicum. The dataset defined nearly 7,000 hookworm genes, including a number of putative developmentally expressed genes and candidates for further study as drug target or vaccine components.

\section{Results}

Nearly 20,000 Ancylostoma derived ESTs were submitted to GenBank between 1999 and 2003 [see Additional file 1]. For simplicity, the results and analysis described are presented in the same order beginning with A. caninum and followed by A. ceylanicum, except where specified.

\section{EST acquisition and NemaGene organization}

ESTs originated from 7 cDNA libraries, representing three and two life-cycle stages respectively (Table 1). Clustering, implemented to reduce data redundancy and improve sequence quality and length, grouped ESTs into contigs which were further organized into clusters (Table 1), providing a non-redundant catalog of represented genes. ESTs within a contig derive from nearly identical transcripts while contigs within a cluster may arise from splice isoforms, alleles, or closely related paralogs [17]. Fifty-one potentially chimeric ESTs were discarded. Clusters ranged in size from a single EST to 203 and 323 for A. caninum and $A$. ceylanicum respectively (Figure 1). Most clusters for each species (72\% and 55\%) have ten or fewer ESTs. GC content for coding sequences was similar in the two species (44\% and 48\%) and consistent with other Clade V nematodes like C. elegans and C. briggsae [18].

The number of clusters may overestimate gene discovery, as one gene may be represented by multiple non-overlapping clusters (fragmentation). By using C. elegans as a reference genome (19,522 genes; [10]) and discounting for fragmentation calculated as $4.5 \%$ and $6.5 \%$ respectively [17], the estimated gene numbers were reduced to 3,840 for $A$. caninum and 3,149 for $A$. ceylanicum giving a gene discovery rate of $41 \%(3,840 \times 100 / 9,283)$ and $30 \%$ $(3,149 \times 100 / 10,588)$. These numbers also indicate $20 \%$ and $16 \%$ representation of all genes for each species respectively. The number of genes in common for more stage-specific Ancylostoma libraries analysed was as low as $9 \%$ and $11 \%$ (Figure 2). This may reflect the EST sample size or stage-specific expression, as will be discussed. In 
Table I: Ancylostoma libraries sequenced and their properties

\begin{tabular}{|c|c|c|c|c|c|}
\hline & Nematode stage (vector or SLI based) & ESTs Submitted & Nucleotides (million) & Mean read length (bp) & StDev \\
\hline \multirow[t]{5}{*}{ A. caninum } & Infective L3 (UniZap) & 5,679 & 2,632 & 358 & 109 \\
\hline & Tissue arrested L3 (SLI) & 820 & 0,318 & 344 & 151 \\
\hline & Serum stimulated L3 (pAMP) & 2,832 & 1,273 & 441 & 150 \\
\hline & Overall & 9,331 & 4,223 & 381 & 137 \\
\hline & Contigs - 5,484 (4,020 clusters) & & & 502 & 168 \\
\hline \multirow[t]{7}{*}{ A. ceylanicum } & Infective L3 ( $\lambda$ ZAP II) & 3,359 & 2,021 & 500 & 127 \\
\hline & Infective L3 (SLI) & 3,306 & 1,550 & 400 & 143 \\
\hline & Adult (MI SLI) & 629 & 0,319 & 460 & 134 \\
\hline & Adult (M2 SLI) & 480 & 0,255 & 467 & $|3|$ \\
\hline & Adult ( $\lambda Z A P ~ I I)$ & 2,817 & 1,646 & 500 & 139 \\
\hline & Overall & $|0,59|$ & 5,791 & 465 & 135 \\
\hline & Contigs - 4,953 (3,369 clusters) & & & 572 & 179 \\
\hline
\end{tabular}

either case, the results clearly show the advantage gained for gene discovery in Ancylostoma by including diverse life stages in the analysis.

\section{Functional classification based on Gene Ontology and KEGG assignments}

Thirty-four percent of A. caninum and $54 \%$ of A. ceylanicum clusters align to InterPro domains and $21 \%$ and $36 \%$ map to Gene Ontology (GO) respectively. Following this same pattern, A. caninum also had fewer BLAST matches (see below). Seven of the ten most abundantly represented InterPro domains were common to both species (Table 2). GO representation is shown by biological process, cellular component, and molecular function (Table $3)$. Among the most common GO categories are protein metabolism (GO:0019538) and catalytic activity (GO:0003824).

Within Ancylostoma spp. clusters that had extracellular mappings, $70 \%$ and $56 \%$ respectively were in the category of Allergen V5/Tpx-1 proteins (IPR001283) related to the secreted venom proteins from hymenopteran insects (Table 2). The Ancylostoma secreted proteins (ASPs) belong to this large gene family [19], members of which been shown to play roles in host-parasite interactions for both mammalian $[20,21]$ and plant parasitic nematodes [22], and to induce protective responses [6]. ASP-1 is one of the major proteins secreted by serum-stimulated $A$. caninum iL3 [12]. In addition, four A. ceylanicum clusters were classified in extracellular matrix (GO:0005578) as tissue inhibitor of metalloprotease (TIMP) domain proteins. A TIMP homolog is reported as the most abundant protein in adult hookworm excretory/secretory products and may inhibit host metalloproteases [23].
Ten $\%$ and $15 \%$ unique clusters for A. caninum and A. ceylanicum respectively, mapped to 89 metabolic pathways grouped in 11 categories (Table 4). Complete listings and graphical representations of the KEGG mappings are available at http://www.nematode.net. Pathways well represented by both species include glycolysis/gluconeogenesis, citrate cycle, oxidative phosphorylation and fatty acid biosynthesis and metabolism. KEGG analysis (Table 4) also suggests specific biochemical differences among Ancylostoma stages. For example, while serum stimulated L3-specific clusters make up to $27 \%$ of all AC clusters, they account for $40 \%$ of all KEGG pathway mappings. In contrast, iL3-specific clusters that account for $55 \%$ of all AC clusters make-up only $38 \%$ of KEGG pathway mappings. It is unclear whether the predominance of enzyme mappings from the ssL3 stage versus iL3 stage is indicative of greater metabolic activity, greater metabolic complexity, differences in library construction methods, or other differences.

\section{Homologs in other organisms, orthologs within Ancylostoma spp. and estimates of selective pressure} Within A. ceylanicum clusters, $83 \%$ had homology to proteins from other organisms as compared to only $66 \%$ for A. caninum (Figure 3). To investigate why contigs from closely related species would show a difference in identified homologies, we compared sequence lengths and the open reading frame (ORF) lengths of contigs with and without homologies in both species. EST lengths and contig lengths, respectively, were shorter for A. caninum (410 and 549 nucleotides) than for A. ceylanicum (490 and 637 nucleotides). The differences were even more striking for ORFs (Figure 4). Hence, A. caninum contigs very likely identify fewer homologs because these sequences are shorter, contain smaller ORFs, and proba- 


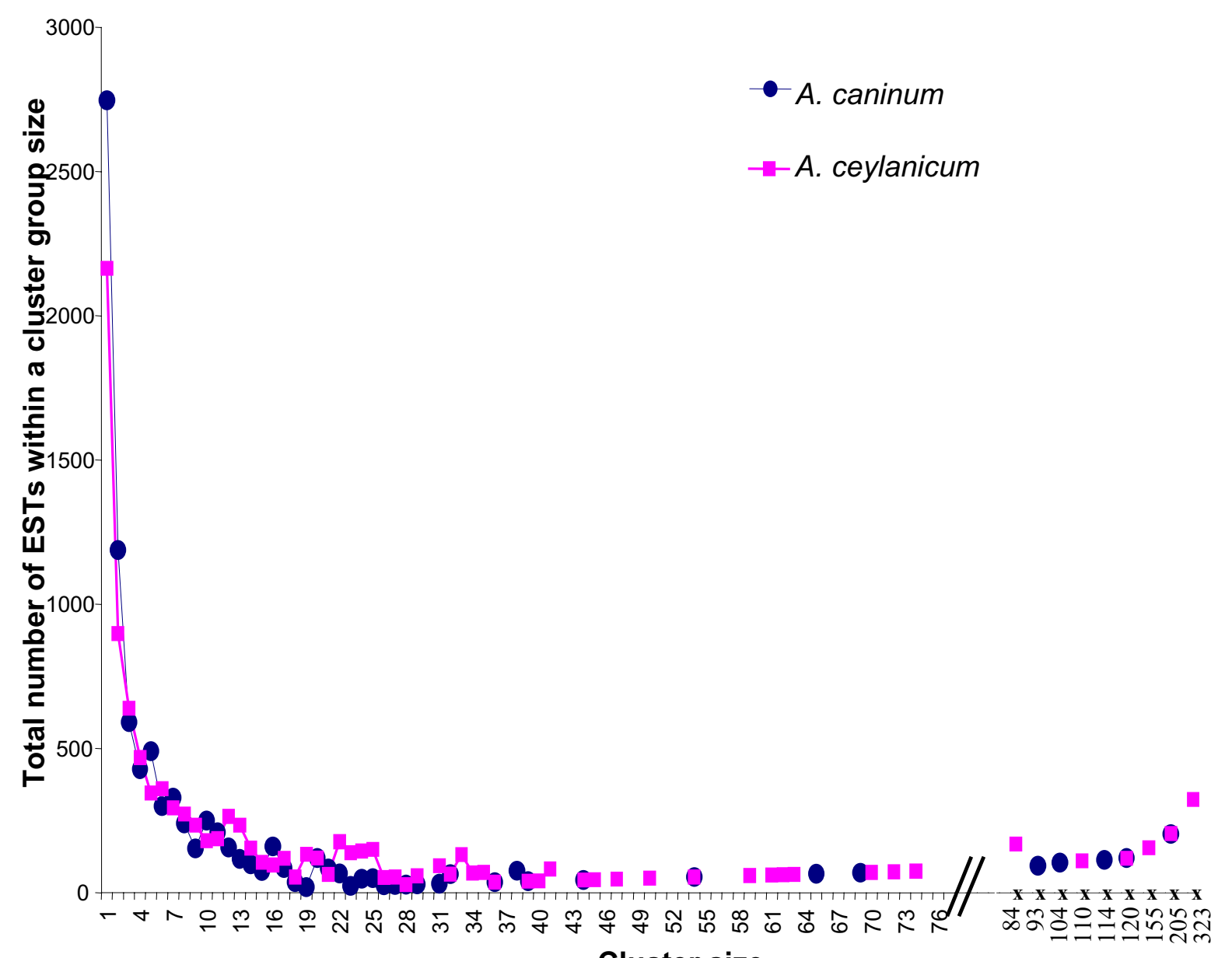

Figure I

Ancylostoma NemaGene v2.0 clustering showing the distribution of ESTs by cluster size. For example, there are three A. caninum cluster of size 22 containing a sum of 66 ESTs and there were eight $A$. ceylanicum clusters of size 22 containing a sum of I76 ESTs. Cluster size (x-axis) is shown to scale for I-75 members, with the size of larger clusters indicated.

bly include more 3' UTR versus the superior quality dataset from A. ceylanicum. Most likely, differences in library construction and sampling rather than intrinsic differences between the species explain this discrepancy. Accounting for such differences is important as it keeps analysis focused upon interesting features of the dataset related to the organisms' biology rather than artifactual differences arising from data collection.

The distribution of identified homologs (Figure 3) was consistent with earlier observations [17]. Besides C. elegans, one of the more informative nematode datasets for this study is a collection of 4,780 ESTs from the human hookworm Necator americanus to which homologies were commonly found (42\% and 38\% respectively). Within Ancylostoma itself homologies were common with $34 \%$ of total A. caninum clusters matching the A. ceylanicum dataset and $44 \%$ of total $A$. ceylanicum clusters matching $A$. caninum. Searching for putative orthologs between all $A$. caninum and A. ceylanicum contigs resulted in 1,304 reciprocal best TBLASTX hits. The ortholog pair members were very similar in GC composition (46\% and 47\%) and the average length of alignment was $327 \mathrm{bp}$. All ortholog pairs (574) were under purifying selection $(\mathrm{dN} / \mathrm{dS}<1$; Figure 5$)$ and the average $\mathrm{dS}$ was $0.65 \pm 0.83$ and $\mathrm{dN}$ was $0.11 \pm 0.2$. The average $\mathrm{dN} / \mathrm{dS}$ ratio $(\sim 0.17)$ is higher than 

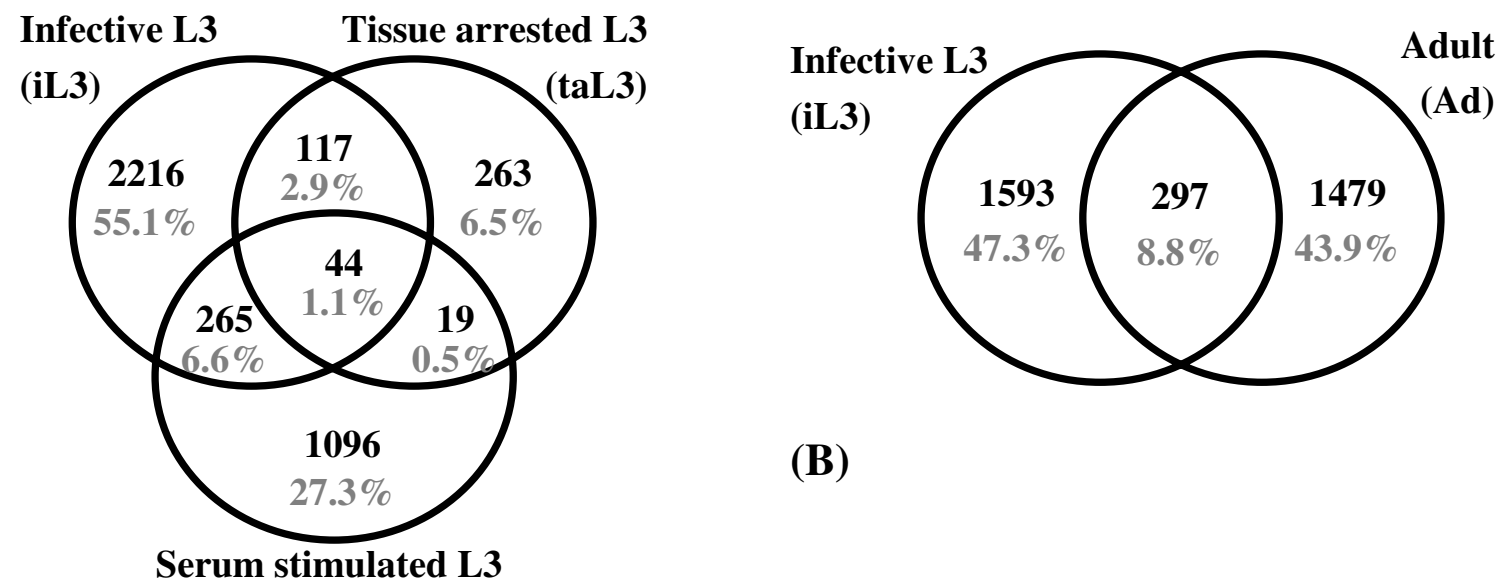

(B)

\section{(A)}

(ssL3)

\section{Figure 2}

Venn diagram of A. caninum (A) and A. ceylanicum (B) clusters, based on stage of origin of each cluster's EST members. The majority of clusters are represented by only one stage in this investigation, though greater depth of sampling would likely increase representation by multiple stages.

Table 2: Most abundantly represented protein domains in A. caninum and A. ceylanicum datasets

\begin{tabular}{|c|c|c|c|}
\hline Species & InterPro ID & Clusters \# & Domain descriptor \\
\hline \multicolumn{4}{|c|}{ A. caninum } \\
\hline & IPR00I 230 & $|4|$ & Prenyl group, CAAX box, attachment site \\
\hline & IPR00I687 & 66 & ATP/GTP-binding site motif A (P-loop) \\
\hline & IPR000694 & 62 & Proline-rich region \\
\hline & IPR00I 472 & 51 & Bipartite nuclear localization signal \\
\hline & IPR000345 & 29 & Cytochrome $\mathrm{c}$ heme-binding site \\
\hline & IPR00I 283 & 25 & Allergen $\mathrm{V} 5 / \mathrm{Tpx}-\mathrm{I}$ related \\
\hline & IPR002048 & 24 & Calcium-binding EF-hand \\
\hline & IPR000504 & 21 & RNA-binding region RNP-I (RNA recognition motif) \\
\hline & IPR0007I9 & 19 & Protein kinase \\
\hline & IPR007087 & 17 & $\mathrm{Zn}$-finger, $\mathrm{C} 2 \mathrm{H} 2$ type \\
\hline \multicolumn{4}{|c|}{ A. ceylanicum } \\
\hline & IPR000694 & 214 & Proline-rich region \\
\hline & IPR00I 230 & 153 & Prenyl group, CAAX box, attachment site \\
\hline & IPR00I687 & 125 & ATP/GTP-binding site motif A (P-loop) \\
\hline & IPR000345 & 50 & Cytochrome $\mathrm{c}$ heme-binding site \\
\hline & IPR006209 & 48 & EGF-like domain \\
\hline & IPR000504 & 37 & RNA-binding region RNP-I (RNA recognition motif) \\
\hline & IPR00I 283 & 34 & Allergen $\mathrm{V} 5 / \mathrm{Tpx}-\mathrm{I}$ related \\
\hline & IPR00I 472 & 32 & Bipartite nuclear localization signal \\
\hline & IPR000I69 & 32 & Eukaryotic thiol (cysteine) protease \\
\hline & IPR00I534 & 27 & Transthyretin-like \\
\hline
\end{tabular}


Table 3: GO mappings for $A$. caninum and $A$. ceylanicum clusters

\begin{tabular}{|c|c|c|c|c|}
\hline \multirow{2}{*}{ Categories and subcategories } & \multicolumn{2}{|c|}{ A. caninum } & \multicolumn{2}{|c|}{ A. ceylanicum } \\
\hline & Representation & $\begin{array}{l}\% \text { Representation of } \\
\text { total }\end{array}$ & Representation & $\begin{array}{c}\% \text { Representation of } \\
\text { total }\end{array}$ \\
\hline \multicolumn{5}{|l|}{ biological process } \\
\hline cellular process & 192 & 4.80 & 238 & 4.36 \\
\hline cell communication & 62 & 1.55 & 66 & 1.21 \\
\hline cell motility & 1 & 0.03 & 0 & 0.00 \\
\hline cell death & 1 & 0.03 & 1 & 0.02 \\
\hline cell growth and/or maintaince & 140 & 3.50 & 180 & 3.30 \\
\hline transport & 119 & 2.98 & 153 & 2.80 \\
\hline cell organization and biogenesis & 21 & 0.53 & 32 & 0.59 \\
\hline cell proliferation & 4 & 0.10 & 6 & 0.11 \\
\hline cell homeostasis & 1 & 0.03 & 4 & 0.07 \\
\hline physiological process & 579 & 14.48 & 785 & 14.38 \\
\hline response to endogenous stimulus & 1 & 0.03 & 5 & 0.09 \\
\hline response to external stimulus & 12 & 0.30 & 16 & 0.29 \\
\hline response to stress & 8 & 0.20 & 14 & 0.26 \\
\hline death & 1 & 0.03 & 1 & 0.02 \\
\hline metabolism & 466 & 11.65 & 653 & 11.96 \\
\hline hemostasis & 1 & 0.03 & 0 & 0.00 \\
\hline homeostasis & 3 & 0.08 & 4 & 0.07 \\
\hline secretion & 0 & 0.00 & 1 & 0.02 \\
\hline development & 11 & 0.28 & 18 & 0.33 \\
\hline \multicolumn{5}{|l|}{ cellular component } \\
\hline cell & 327 & 8.18 & 385 & 7.05 \\
\hline intracellular & 212 & 5.30 & 277 & 5.08 \\
\hline cytoplasm & 166 & 4.15 & 181 & 3.32 \\
\hline nucleus & 45 & 1.13 & 84 & 1.54 \\
\hline ribonucleoprotein complex & 102 & 2.55 & 102 & 1.87 \\
\hline respiratory chain complex & 4 & 0.10 & 5 & 0.09 \\
\hline chromosome & 8 & 0.20 & 13 & 0.24 \\
\hline thylakoid & 0 & 0.00 & 1 & 0.02 \\
\hline membrane & 146 & 3.65 & 146 & 2.67 \\
\hline extracellular & 33 & 0.83 & 50 & 0.92 \\
\hline Unlocalized & 1 & 0.03 & 7 & 0.13 \\
\hline \multicolumn{5}{|l|}{ molecular function } \\
\hline binding & 323 & 8.08 & 521 & 9.55 \\
\hline carbohydrate binding & 6 & 0.15 & 20 & 0.37 \\
\hline lipid binding & 6 & 0.15 & 12 & 0.22 \\
\hline metal ion binding & 56 & 1.40 & 72 & 1.32 \\
\hline nucleic acid binding & 109 & 2.73 & 201 & 3.68 \\
\hline nucleotide binding & 133 & 3.33 & 214 & 3.92 \\
\hline protein binding & 11 & 0.28 & 22 & 0.40 \\
\hline apoptosis regulator activity & 1 & 0.03 & 1 & 0.02 \\
\hline chaperone activity & 5 & 0.13 & 10 & 0.18 \\
\hline cell adhesion molecule activity & 2 & 0.05 & 1 & 0.02 \\
\hline catalytic activity & 293 & 7.33 & 445 & 8.15 \\
\hline enzyme regulator activity & 24 & 0.60 & 35 & 0.64 \\
\hline molecular function unknown & 38 & 0.95 & 46 & 0.84 \\
\hline motor activity & 3 & 0.08 & 12 & 0.22 \\
\hline signal transducer activity & 55 & 1.38 & 61 & 1.12 \\
\hline structural molecule activity & 107 & 2.68 & 127 & 2.33 \\
\hline transcription regulator activity & 19 & 0.48 & 33 & 0.60 \\
\hline translation regulator activity & 14 & 0.35 & 17 & 0.31 \\
\hline transporter activity & 128 & 3.20 & 180 & 3.30 \\
\hline
\end{tabular}


Table 4: Kegg Biochemical pathway mappings for A. caninum and A. ceylanicum clusters

AC Clusters per library AE Clusters per library

I. Carbohydrate metabolism

I.I Glycolysis / Gluconeogenesis

I.2 Citrate cycle (TCA cycle)

I.3 Pentose phosphate pathway

I.4 Pentose and glucuronate interconversions

I.5 Fructose and mannose metabolism

I.6 Galactose metabolism

I.7 Ascorbate and aldarate metabolism

I.8 Pyruvate metabolism

I.9 Glyoxylate and dicarboxylate metabolism

I. 10 Propanoate metabolism

I.I I Butanoate metabolism

I. 12 C5-Branched dibasic acid metabolism

I.I 3 Inositol metabolism

2. Energy metabolism

2.I Oxidative phosphorylation

2.2 ATP synthesis

2.4 Carbon fixation

2.5 Reductive carboxylate cycle (CO2 fixation)

2.6 Methane metabolism

2.7 Nitrogen metabolism

2.8 Sulfur metabolism

3. Lipid metabolism

3.I Fatty acid biosynthesis (path I)

3.2 Fatty acid biosynthesis (path 2)

3.3 Fatty acid metabolism

3.4 Synthesis and degradation of ketone bodies

3.5 Sterol biosynthesis

3.6 Bile acid biosynthesis

3.8 Androgen and estrogen metabolism

4. Nucleotide metabolism

4.I Purine metabolism

4.2 Pyrimidine metabolism

4.3 Nucleotide sugars metabolism

5. Amino acid metabolism

5.I Glutamate metabolism

5.2 Alanine and aspartate metabolism

5.3 Glycine, serine and threonine metabolism

5.4 Methionine metabolism

5.5 Cysteine metabolism

5.6 Valine, leucine and isoleucine degradation 5.7 Valine, leucine and isoleucine biosynthesis

5.8 Lysine biosynthesis

5.9 Lysine degradation

5.10 Arginine and proline metabolism

5.II Histidine metabolism

5.12 Tyrosine metabolism

5. I3 Phenylalanine metabolism

5. 14 Tryptophan metabolism

5.15 Phenylalanine, tyrosine and tryptophan biosynthesis

5.16 Urea cycle and metabolism of amino groups

6. Metabolism of other amino acids

6.I beta-Alanine metabolism

6.2 Taurine and hypotaurine metabolism

6.3 Aminophosphonate metabolism

6.4 Selenoamino acid metabolism

\begin{tabular}{|c|c|c|c|c|c|c|c|c|c|c|}
\hline 23 & 13 & 0 & 5 & 5 & 22 & 25 & 10 & 11 & 4 & 23 \\
\hline 17 & 8 & 0 & 4 & 5 & 16 & 15 & 4 & 8 & 3 & 15 \\
\hline 9 & 3 & 0 & 4 & 2 & 9 & 12 & 5 & 3 & 4 & 8 \\
\hline 8 & 3 & 0 & 3 & 2 & 9 & 9 & 5 & 4 & 0 & 8 \\
\hline 14 & 6 & 0 & 4 & 4 & 15 & 20 & 7 & 11 & 2 & 15 \\
\hline 10 & 4 & 0 & 4 & 2 & 8 & 12 & 6 & 5 & I & 12 \\
\hline 7 & 4 & 0 & 2 & I & 4 & 5 & 5 & 0 & 0 & 4 \\
\hline 25 & II & 0 & 11 & 3 & 23 & 27 & 8 & 17 & 2 & 26 \\
\hline 13 & 6 & 0 & 5 & 2 & 14 & 9 & I & 5 & 3 & 17 \\
\hline 22 & 7 & I & 10 & 4 & 20 & 25 & II & 8 & 6 & 22 \\
\hline 22 & 9 & I & 7 & 5 & 23 & 29 & 14 & 14 & I & 26 \\
\hline 4 & 3 & 0 & I & 0 & 2 & 2 & I & 0 & I & I \\
\hline 6 & 2 & 0 & I & 3 & 4 & 7 & 2 & 3 & 2 & 4 \\
\hline 24 & 7 & 0 & 6 & II & 11 & 33 & 10 & 14 & 9 & 13 \\
\hline 8 & 2 & 0 & 3 & 3 & I & 11 & 4 & 3 & 4 & 1 \\
\hline 11 & 3 & 0 & 3 & 5 & 11 & 11 & 3 & 5 & 3 & 13 \\
\hline 12 & 7 & 0 & I & 4 & 8 & 9 & 2 & 4 & 3 & 7 \\
\hline 6 & 4 & 0 & 0 & 2 & 5 & 6 & 0 & 4 & 2 & 6 \\
\hline II & 2 & 0 & 5 & 4 & 14 & 12 & 5 & 5 & 2 & 15 \\
\hline 5 & 1 & 0 & I & 3 & 9 & 6 & 3 & I & 2 & 9 \\
\hline 6 & 2 & 0 & 3 & I & 11 & 7 & 3 & 3 & I & 6 \\
\hline 8 & 2 & 0 & 5 & I & 6 & 6 & 3 & 2 & I & 5 \\
\hline 14 & 6 & I & 6 & I & 17 & 21 & 13 & 7 & I & 16 \\
\hline 2 & 0 & 0 & 1 & I & 2 & 8 & 4 & 3 & 1 & 3 \\
\hline 4 & 1 & I & 2 & 0 & 4 & 4 & 2 & 2 & 0 & 9 \\
\hline II & 7 & I & 2 & I & II & 11 & 6 & 4 & I & 10 \\
\hline 7 & 5 & 0 & 2 & 0 & 9 & 7 & 4 & 3 & 0 & 8 \\
\hline 27 & 11 & 0 & 11 & 5 & 28 & 32 & 14 & II & 7 & 32 \\
\hline 16 & 8 & I & 5 & 2 & 15 & 22 & 9 & 12 & I & 22 \\
\hline 6 & 4 & 0 & 0 & 2 & 3 & 4 & 2 & 2 & 0 & 4 \\
\hline II & 3 & 0 & 5 & 3 & 14 & 16 & 8 & 7 & I & 18 \\
\hline 14 & 1 & 0 & 8 & 5 & 15 & 14 & 5 & 6 & 3 & 15 \\
\hline 19 & 7 & 0 & 9 & 3 & 14 & 21 & 8 & 10 & 3 & 24 \\
\hline 6 & 1 & 0 & 4 & I & 9 & 6 & 5 & I & 0 & 8 \\
\hline 8 & 2 & 0 & 2 & 4 & 11 & 7 & 5 & 2 & 0 & 9 \\
\hline 16 & 3 & I & 8 & 4 & 16 & 22 & 11 & 6 & 5 & 18 \\
\hline 7 & 1 & 0 & 4 & 2 & 7 & 9 & 6 & 2 & I & 8 \\
\hline 11 & 1 & 0 & 6 & 4 & 10 & 9 & 4 & 3 & 2 & 8 \\
\hline 19 & 8 & 0 & 8 & 3 & 14 & 19 & 12 & 6 & I & 17 \\
\hline 18 & 4 & 0 & 8 & 6 & 20 & 22 & 11 & 7 & 4 & 20 \\
\hline 10 & 4 & 0 & 4 & 2 & 8 & 10 & 5 & 4 & I & 8 \\
\hline 18 & 8 & 0 & 7 & 3 & 19 & 19 & 11 & 5 & 3 & 19 \\
\hline 13 & 5 & 0 & 3 & 5 & 11 & 14 & 7 & 6 & I & 12 \\
\hline 17 & 8 & 0 & 8 & I & 15 & 22 & 16 & 4 & 2 & 18 \\
\hline 5 & 1 & 0 & 2 & 2 & 6 & 4 & 2 & 0 & 2 & 7 \\
\hline 10 & 1 & 0 & 5 & 4 & 14 & 10 & 2 & 6 & 2 & II \\
\hline 14 & 4 & I & 7 & 2 & 13 & 11 & 8 & I & 2 & 10 \\
\hline I & 0 & 0 & 0 & I & I & 2 & 2 & 0 & 0 & 3 \\
\hline 4 & 0 & 0 & 3 & I & 3 & 5 & 2 & 3 & 0 & 5 \\
\hline 7 & 0 & 0 & 4 & 3 & 12 & 12 & 6 & 4 & 2 & 15 \\
\hline
\end{tabular}


Table 4: Kegg Biochemical pathway mappings for A. caninum and A. ceylanicum clusters (Continued)

\begin{tabular}{|c|c|c|c|c|c|c|c|c|c|c|c|c|}
\hline 6.5 Cyanoamino acid metabolism & 2 & $T$ & 0 & $T$ & 0 & $T$ & 7 & 5 & 1 & $T$ & 6 & 19 \\
\hline 6.6 D-Glutamine and D-glutamate metabolism & 2 & 0 & 0 & I & I & 2 & 2 & I & 0 & I & 2 & 12 \\
\hline 6.7 D-Arginine and D-ornithine metabolism & 3 & I & 0 & 0 & 2 & 2 & 3 & 0 & 2 & I & 2 & 10 \\
\hline 6.9 Glutathione metabolism & 5 & 1 & 0 & 0 & 4 & 4 & 9 & 5 & 3 & I & 6 & 27 \\
\hline \multicolumn{13}{|l|}{ 7. Metabolism of complex carbohydrates } \\
\hline 7.I Starch and sucrose metabolism & 18 & 2 & 0 & 13 & 3 & 18 & 20 & 13 & 6 & I & 20 & 75 \\
\hline $7.2 \mathrm{~N}$-Glycans biosynthesis & 7 & 4 & 0 & 1 & 2 & 7 & 7 & 2 & 4 & I & 9 & 27 \\
\hline 7.3 O-Glycans biosynthesis & 3 & I & 0 & I & I & 2 & 6 & 5 & I & 0 & 3 & 8 \\
\hline 7.5 Aminosugars metabolism & 6 & 3 & 0 & 2 & I & 6 & 10 & 5 & 5 & 0 & 10 & 39 \\
\hline 7.8 Glycosaminoglycan degradation & I & I & 0 & 0 & 0 & I & I & I & 0 & 0 & $\mathrm{I}$ & 13 \\
\hline 7.9 Chondroitin / Heparan sulfate biosynthesis & 5 & 3 & 0 & I & I & 4 & 6 & 2 & 4 & 0 & 4 & 18 \\
\hline 7.10 Keratan sulfate biosynthesis & I & 0 & 0 & 1 & 0 & I & 2 & I & I & 0 & I & 6 \\
\hline \multicolumn{13}{|l|}{ 8. Metabolism og complex lipids } \\
\hline 8.I Glycerolipid metabolism & 24 & 10 & 0 & 9 & 5 & 22 & 25 & 10 & 13 & 2 & 22 & 80 \\
\hline 8.3 Inositol phosphate metabolism & 8 & 4 & 0 & 4 & 0 & 4 & 8 & 5 & 2 & I & 3 & 25 \\
\hline 8.4 Sphingophospholipid biosynthesis & I & I & 0 & 0 & 0 & I & 2 & I & I & 0 & 2 & 8 \\
\hline 8.5 Phospholipid degradation & 3 & 2 & 0 & 0 & I & 3 & I & I & 0 & 0 & I & 11 \\
\hline 8.6 Sphingoglycolipid metabolism & 11 & 1 & I & 9 & 0 & 7 & 10 & 8 & 2 & 0 & 4 & 20 \\
\hline 8.9 Globoside metabolism & 2 & 1 & 0 & 1 & 0 & 2 & 2 & I & I & 0 & I & 12 \\
\hline 8.II Prostaglandin and leukotriene metabolism & 8 & 2 & 0 & I & 5 & 8 & 7 & 4 & 3 & 0 & 6 & 19 \\
\hline \multicolumn{13}{|l|}{ 9. Metabolism of cofactors and vitamins } \\
\hline 9.2 Riboflavin metabolism & 4 & I & 0 & 3 & 0 & 2 & 2 & 2 & 0 & 0 & 2 & 13 \\
\hline 9.3 Vitamin B6 metabolism & 6 & 4 & 0 & I & I & 3 & 6 & 4 & I & I & 5 & 23 \\
\hline 9.4 Nicotinate and nicotinamide metabolism & 11 & 2 & 0 & 7 & 2 & 7 & 15 & 8 & 7 & 0 & 7 & 32 \\
\hline 9.5 Pantothenate and CoA biosynthesis & 8 & 2 & 0 & 4 & 2 & 9 & 8 & 6 & 2 & 0 & 7 & 27 \\
\hline 9.7 Folate biosynthesis & 5 & 2 & I & 0 & 2 & 5 & 6 & 1 & 4 & I & 5 & 25 \\
\hline 9.8 One carbon pool by folate & 5 & 3 & 0 & 2 & 0 & 10 & 7 & 3 & 3 & I & 8 & 24 \\
\hline 9.10 Porphyrin and chlorophyll metabolism & 18 & 4 & 0 & 10 & 4 & 12 & 27 & 15 & 8 & 4 & 13 & 56 \\
\hline 9.1I Ubiquinone biosynthesis & 19 & 10 & 0 & 5 & 4 & 13 & 28 & II & 14 & 3 & 14 & 22 \\
\hline \multicolumn{13}{|l|}{ 10. Biosynthesis of secondary metabolites } \\
\hline I0.1 Terpenoid biosynthesis & 0 & 0 & 0 & 0 & 0 & 0 & 2 & 0 & 2 & 0 & 4 & 12 \\
\hline 10.3 Flavonoids, stilbene and lignin biosynthesis & 6 & 3 & 0 & 1 & 2 & 7 & 8 & 5 & 3 & 0 & 7 & 39 \\
\hline I0.4 Alkaloid biosynthesis I & 5 & 2 & 0 & 3 & 0 & 6 & 3 & 3 & 0 & 0 & 5 & 36 \\
\hline 10.8 Streptomycin biosynthesis & 2 & 0 & 0 & 2 & 0 & 3 & 4 & 2 & I & I & 4 & 14 \\
\hline 10.9 Erythromycin biosynthesis & 2 & 0 & 0 & 2 & 0 & 3 & 3 & 2 & I & 0 & 3 & 6 \\
\hline \multicolumn{13}{|l|}{ II. Biodegradation of xenobiotics } \\
\hline I I.4 Nitrobenzene degradation & 4 & I & 0 & 3 & 0 & 5 & 4 & 2 & I & I & 3 & 17 \\
\hline II.9 Tetrachloroethene degradation & 6 & 4 & 0 & 1 & I & 3 & 2 & 2 & 0 & 0 & 3 & 5 \\
\hline II.I0 Styrene degradation & 4 & 2 & 0 & 2 & 0 & 3 & 6 & 5 & 0 & I & 5 & 18 \\
\hline II.I gamma-Hexachlorocyclohexane degradation & 6 & 3 & 0 & 3 & 0 & 5 & 5 & 3 & 2 & 0 & 4 & 12 \\
\hline II.I Fluorene degradation & 3 & 1 & 0 & 2 & 0 & 4 & 2 & 2 & 0 & 0 & 2 & 13 \\
\hline I I.2 Benzoate degradation via CoA ligation & 22 & 8 & I & 10 & 3 & 18 & 25 & 14 & 10 & I & 18 & 38 \\
\hline II.2 Benzoate degradation via hydroxylation & 7 & 2 & 0 & 5 & 0 & 7 & 5 & 4 & 1 & 0 & 5 & 45 \\
\hline
\end{tabular}

${ }^{\mathrm{a} A}$. caninum - 839 multiple and 786 unique mappings; A. ceylanicum - 957 multiple and 840 unique mappings. ${ }^{b}$ Cluster, ${ }^{c}$ Enzymes

that reported for C. briggsae/C. elegans ( 0.06; [18]), and closer to that for mouse/human $(0.115 ;[24])$, indicating that the levels of purifying selection are somewhat different. In addition, to examine if this purifying selection is more frequently detected in genes with essential function, we cross-referenced the C. elegans genes matched by Ancylostoma orthologs with a list of $C$. elegans genes with available RNA interference (RNAi) information (http:// www.wormbase.org; eg. [25]). Of the $67 \%$ of the orthologous genes matching $C$. elegans genes with available RNAi data, $45 \%$ had an observable phenotype after transcript knock-down. A vast majority of the observed phenotypes were severe ( $88 \%$ sterility and embryonic lethality). Ancy- lostoma orthologs matching C. elegans genes that had phenotypes showed a somewhat lower $\mathrm{dN} / \mathrm{dS}$ ratio than those matching genes that remained wild type after RNAi treatment, though the difference was not statistically significant at $\mathrm{P}<0.05$ (0.09 vs. 0.14 ; sign. diff. at $\mathrm{P}<0.2$ ).

In a 4-way comparison of orthologs in C. elegans, C. briggsae, A. caninum, and A. ceylanicum, the phylogenetic distance between $A$. caninum and A. ceylanicum is almost identical to that between C. elegans and C. briggsae and the distance between the two genera is just over four times the within genera distance (Figure 6). Average branch lengths for the set of 452 orthologous proteins did not show a sig- 


\section{C. elegans}

2130, $80.5 \%$

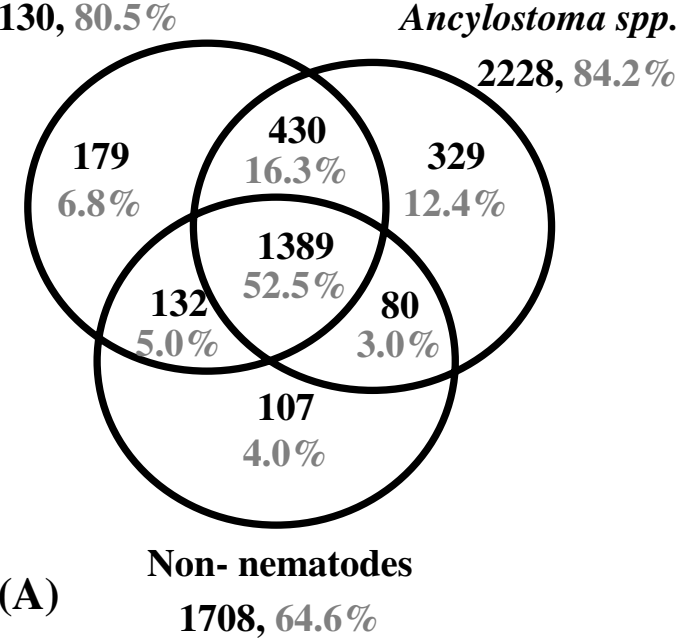

C. elegans

2483, $88.6 \%$

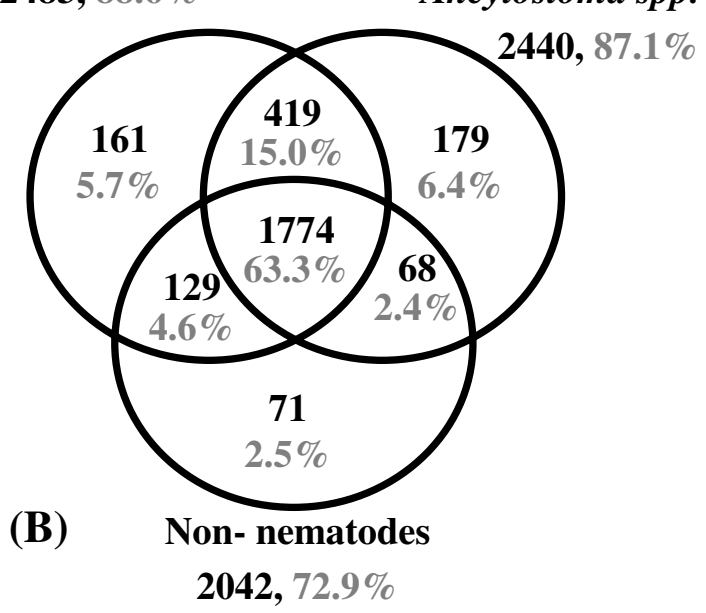

\section{Figure 3}

Venn diagram showing distribution of $A$. caninum (A) and A. ceylanicum (B) cluster BLAST matches by database. Amino acid level homologies ( $\geq$ e- 05$)$ were identified to non-Ancylostoma sequences for $65.8 \%(2,646 / 4,020)$ of $A$. caninum and $83.1 \%(2,801 /$ $3,369)$ of $A$. ceylanicum clusters. Databases used are: for $C$. elegans, Wormpep v. 97 and mitochondrial protein sequences; for other nematodes, all GenBank nucleotide data for nematodes except $C$. elegans and Ancylostoma; for non-nematodes, nrGenBank (3/20/2003) with all nematode sequences removed.

nificant difference in relative rate of molecular change. Maximum likelihood trees [26] were constructed for each 4 -way ortholog and relative branch lengths compared between Ancylostoma spp. for both the protein and nucleotide sequences. For protein sequences, 109 trees had equal branch lengths for the hookworm species while 175 trees had longer A. caninum branches and 168 had longer A. ceylanicum branches. To look for differences between genes in the Ancylostoma species, we constructed a distribution of branch length differences between each of the sister species pairs in our tree. Because some genes may be rapidly evolving in all nematode lineages we evaluated a subset of the trees where the difference in branch lengths between $C$. briggsae and C. elegans were less than one standard deviation from the mean but which had significantly different branch lengths in the two Ancylostoma species. This final dataset had 23 genes with significantly longer branch lengths in A. ceylanicum and 16 in A. caninum ( $1 \mathrm{SD}, \mathrm{P}<0.05)$. However the set did not show any significant bias towards either species ( $\mathrm{p}<0.34$, sign test). This suggests there is no significant rate difference in protein evolution between the two hookworms, although some of these genes are relatively rapidly evolving. Repeating the analysis for nucleotide sequences we find marginally significant differences ( $\mathrm{p}<0.08$; sign test).

\section{Using the C. elegans genome to interpret hookworm sequences}

As expected, the C. elegans genome provides the best source of information for interpreting hookworm sequences as a majority of $A$. caninum and A. ceylanicum clusters with BLAST homologies outside Ancylostoma had C. elegans homologs (Figure 3; 25 most conserved nematode genes between each Ancylostoma species and $C$. elegans are available online; [see Additional file 2]). Furthermore, C. elegans orthologs of hookworm genes with available RNAi or other data provide information that may be relevant to understanding the role of the parasite genes. Of all the Ancylostoma clusters with C. elegans homology, 97\% and 92\% matched C. elegans genes with available RNA interference knock-down information http://www.wormbase.org, and in turn 33\% and 37\% of these C. elegans genes produce RNAi phenotypes (versus a rate of only $\sim 15 \%$ phenotypes for all C. elegans genes). 


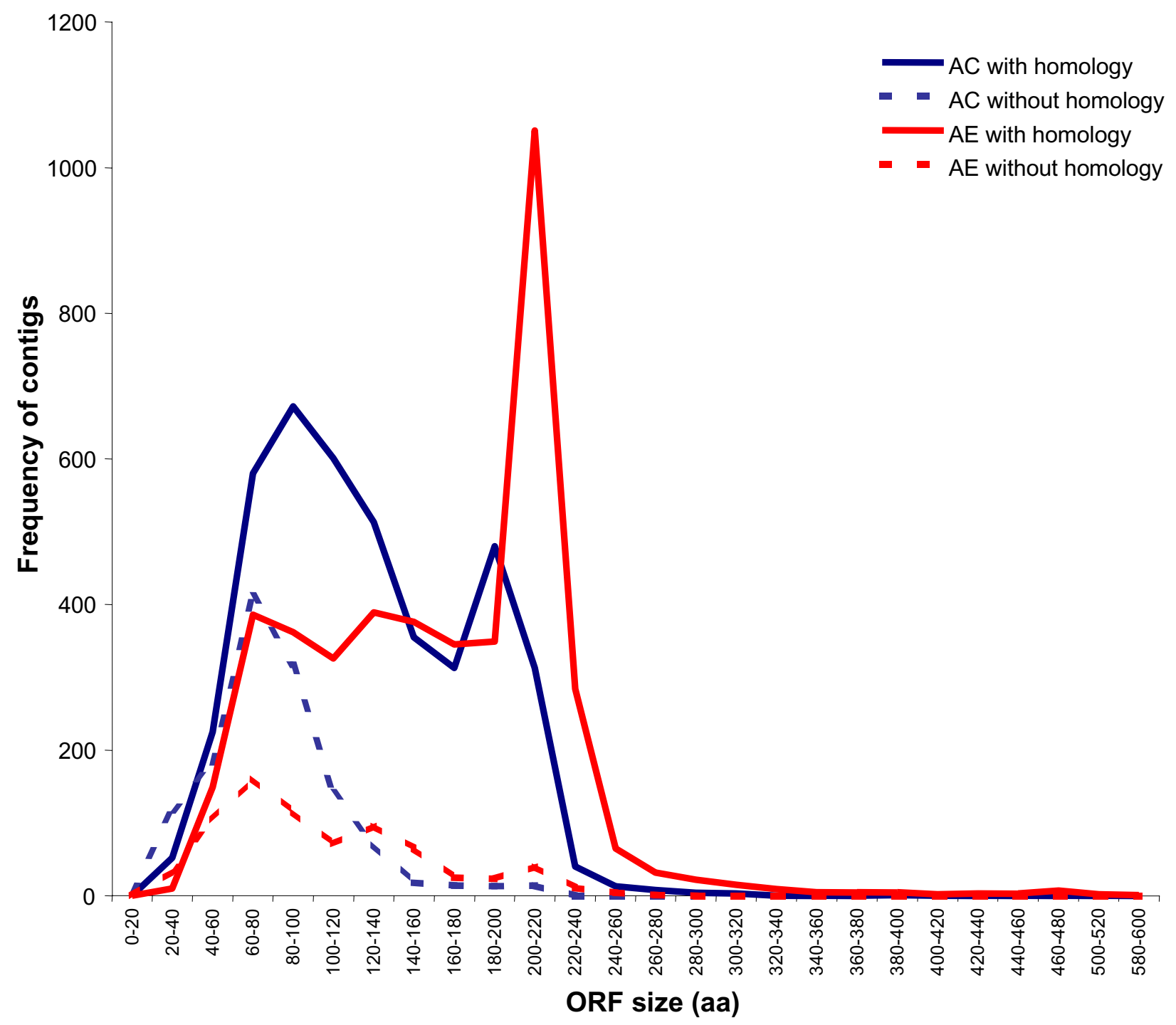

\section{Figure 4}

Distribution of $A$. caninum and A. ceylanicum contigs with and without database amino acid level homology by size of the longest predicted open reading frame (ORF).

Phenotype classification [see Additional file 3] showed that C. elegans genes with expressed Ancylostoma homologs were somewhat more likely to have severe phenotypes [17]. Hence, certain genes in the Ancylostoma datasets encode proteins if disabled may disrupt survival of the parasite. Some examples include abundant clusters (AC00023.cl, AE01104.cl; Table 5 and Table 6). A group of particular interest is proteins that are required for nem- atode survival and lack strong homologies outside of the phyla (nematode-specific), since these targets could provide for nematode control without toxicities to the host or other non-target organisms. Of the Ancylostoma nematode-specific clusters (Figure 3), 85 and 91 respectively had C. elegans matches with RNAi phenotypes. Among these, AC04398.cl and AE00474.cl matched hypothetical protein F42A8.1 (1e-65, 2e-76 respectively), a gene with- 


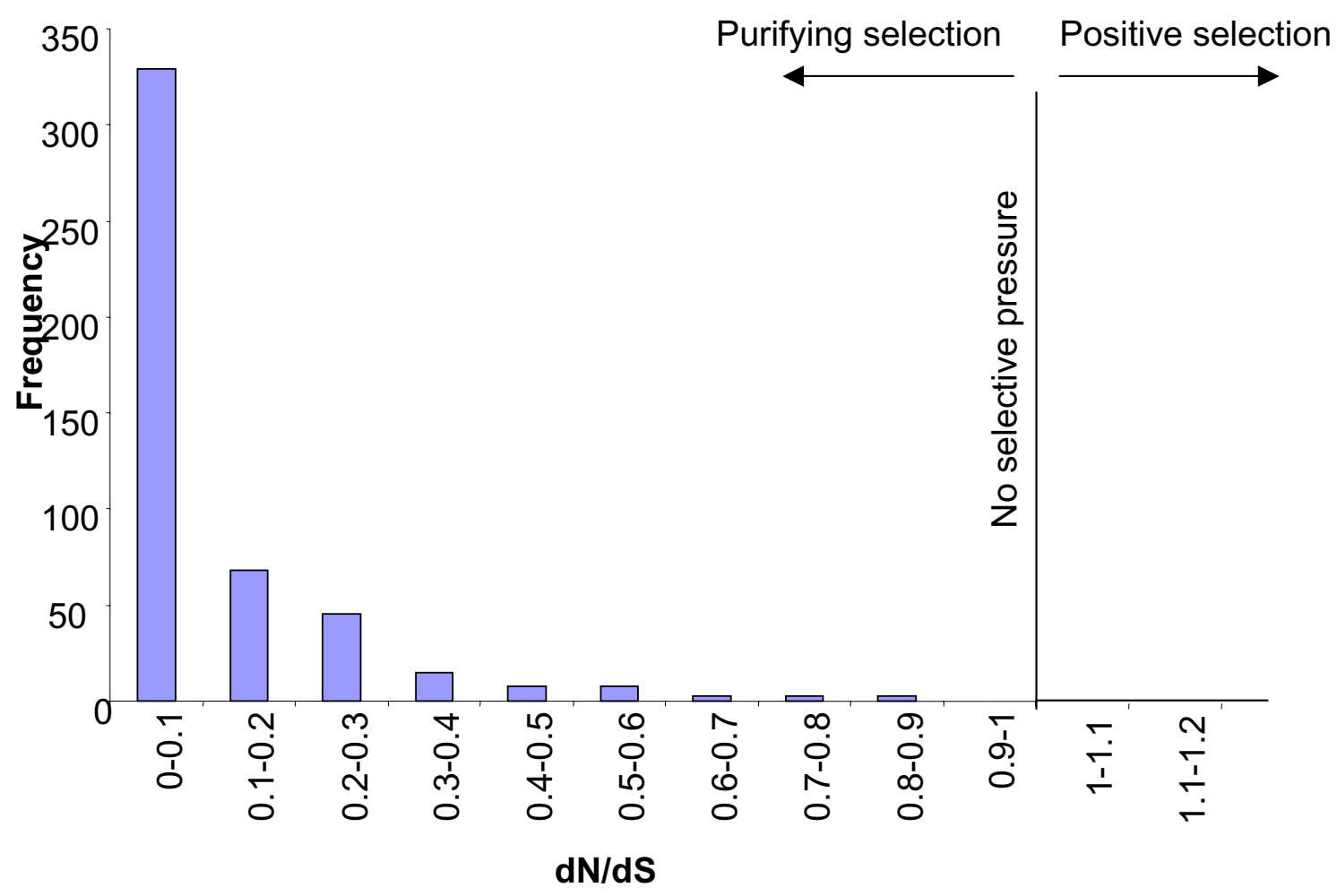

\section{Figure 5}

Distribution of $\mathrm{dN} / \mathrm{dS}$ ratios among Ancylostoma ortholog pairs. $\mathrm{dN}$ and $\mathrm{dS}$ are the rates of nonsynonymous and synonymous amino acid substitutions, respectively.

out a mammalian homolog yet likely involved in multiple developmental processes based on observed mutant phenotypes [25]. Homologs are found in at least 13 nematode species to date including free-living species (3), and parasites of mammals (8) and plants (1). Further analysis will identify additional genes which warrant detailed investigation.

Repeating the analysis in Stein et al. [18] indicates that 6$7 \%$ of C. elegans and C. briggsae proteins are candidate "orphans", lacking homologs outside of the species. We examined whether these genes are truly orphans that have arisen in a Caenorhabditis sub-lineage or are instead genes present in an ancestral nematode that have been lost or evolved beyond recognition in one species. Of candidate orphan proteins, ten from C. elegans (Table 7) and 27 from C. briggsae [see Additional file 4] match A. caninum and/or A. ceylanicum clusters, with three and eight, respec- tively, having matches in both species. Most of the C. elegans orphans are hypothetical proteins of unknown function though some had functional information from InterPro domains (R10E9.3) or mutant phenotypes (ZK686.1). Therefore, at least a portion of the genes identified in either C. elegans or C. briggsae as "orphans" are actually ancestral nematode genes with homologs found in other clade $\mathrm{V}$ species and further clade $\mathrm{V}$ sequencing will likely reveal more such cases.

\section{Abundant transcripts expressed in Ancylostoma species}

The 25 most abundantly represented clusters account for $14 \%$ and $19 \%$ of ESTs for A. caninum and A. ceylanicum respectively. The representation of the abundant transcripts varied from shared to stage-specific (Table 5 and Table 6). Hookworm developmental stages differ in habitat, morphology and behavior, hence highly represented gene transcripts may identify functions that are important 


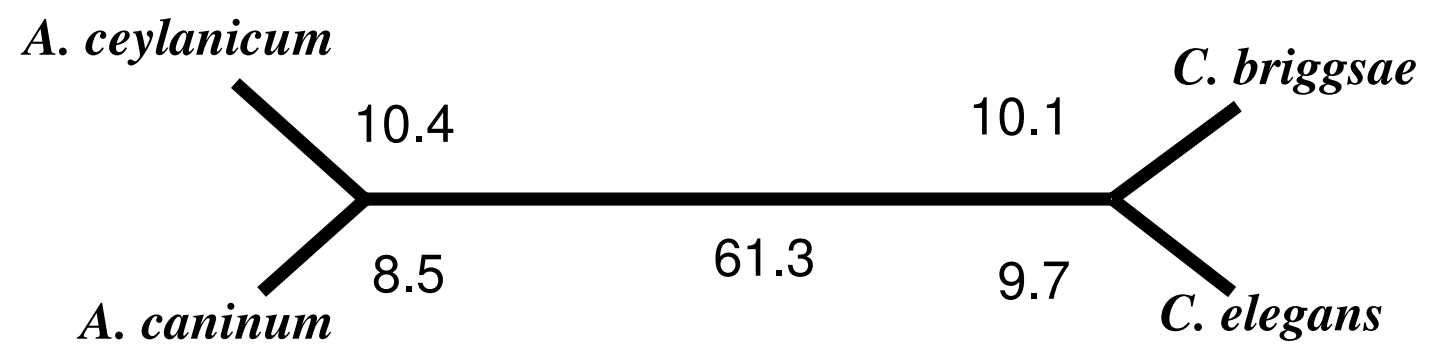

Figure 6

Relative distance based upon protein maximum likelihood. A. ceylanicum to $A$. cananum distance is similar to $C$. elegans to $C$. briggsae distance. Ancylostoma to Caenorhabditis distance for any species is $4.3 \mathrm{X}$ the Ancylostoma to Ancylostoma distance and 4. IX the Caenorhabditis to Caenorhabditis distance. The length of each line segment is proportional to the calculated branch length between the species.

Table 5: The most abundantly represented transcripts in the $A$. caninum cDNA libraries

\begin{tabular}{|c|c|c|c|c|c|c|c|c|}
\hline \multirow{3}{*}{$\begin{array}{l}\text { A. caninum } \\
\text { cluster id }\end{array}$} & \multirow{3}{*}{$\begin{array}{l}\text { ESTs per } \\
\text { cluster }\end{array}$} & \multicolumn{5}{|c|}{ non-redundant GenBank } & \multirow{3}{*}{\multicolumn{2}{|c|}{$\begin{array}{l}\text { C. elegans gene } \\
\text { Wormpep97b }\end{array}$}} \\
\hline & & \multicolumn{3}{|c|}{ ESTs from library } & \multirow[b]{2}{*}{ Best identity descriptor } & \multirow{2}{*}{$\begin{array}{l}\text { Accession } \\
\mathrm{SW} / \mathrm{TR}^{\mathrm{a}}\end{array}$} & & \\
\hline & & iL3 & $\operatorname{taL} 3$ & ssL3 & & & & \\
\hline AC00932.cl & 203 & 186 & 0 & 17 & Ancylostoma duodenale cytochrome oxidase subunit I & CADI0437 & $2 e-304$ & C06G4.2b \\
\hline AC0047I.cl & 120 & 2 & 0 & 118 & C. elegans CMP-sialic acid transporter & 002345 & $2 e-83$ & ZK896.9b \\
\hline $\mathrm{AC} 00048 . \mathrm{cl}$ & 114 & 100 & II & 3 & C. elegans hsp- 12.6 alpha-B-crystallin & Q20165 & $6 e-40$ & $\mathrm{~F} 38 \mathrm{EII} .2^{\mathrm{b}}$ \\
\hline $\mathrm{ACO} 1032 . \mathrm{cl}$ & 104 & 104 & 0 & 0 & Ancylostoma duodenale cytochrome oxidase subunit II & AAL508I4 & $\mathrm{le}-09$ & - \\
\hline $\mathrm{ACO} 103 \mathrm{I} . \mathrm{cl}$ & 93 & 90 & 0 & 3 & Ancylostoma duodenale cytochrome oxidase subunit III & CADI0435 & $2 e-143$ & - \\
\hline AC00807.cl & 69 & 4 & 2 & 63 & Necator americanus ancylostoma secreted protein I precursor & AADI 3340 & $3 e-28$ & F33A8.2 \\
\hline AC00205.cl & 65 & 51 & I & 13 & Ancylostoma duodenale COX2, cytochrome c oxidase subunit II & NP_579953 & $4 e-125$ & F26E4.12 \\
\hline AC00967.cl & 54 & 9 & 0 & 45 & Ancylostoma ceylanicum cathepsin D-like aspartic protease & $\mathrm{AAO} 22152$ & $8 e-174$ & $\mathrm{RI} 2 \mathrm{H} 7.2$ \\
\hline $\mathrm{ACO} / 34 . \mathrm{cl}$ & 44 & 44 & 0 & 0 & C. elegans putative protein, nematode specific & NP_497272 & $9 e-53$ & $\mathrm{~K} 02 \mathrm{~F} 3.9 \mathrm{~b}$ \\
\hline AC01029.cl & 39 & 37 & 2 & 0 & C. elegans stress associated endoplasmic reticulum protein & NP_510604 & $9 e-37$ & $\mathrm{~F} 59 \mathrm{~F} 4.2^{\mathrm{b}}$ \\
\hline $\mathrm{ACO} / 37 . \mathrm{cl}$ & 38 & 37 & 0 & 1 & C. elegans RNA recognition motif & CAB03222 & $4 e-35$ & $\mathrm{R} 06 \mathrm{Cl} .4^{\mathrm{b}}$ \\
\hline AC00023.cl & 38 & 36 & 0 & 2 & C. elegans rpl-2 Ribosomal Proteins L2 & Q9XVF7 & $3 e-148$ & B0250.1b \\
\hline AC00060.cl & 36 & 36 & 0 & 0 & Ancylostoma caninum secreted protein ASP-2 precursor & AAC35986 & $2 e-134$ & FIIC7.3b \\
\hline $\mathrm{ACO} \mid 400 . \mathrm{cl}$ & 32 & 1 & 0 & 31 & C. elegans ham-2 zinc finger protein & NP_50878I & $\mathrm{le}-20$ & C07AI2.1 \\
\hline AC00976.cl & 32 & 29 & 0 & 3 & Tetrahymena pigmentosa metallothionein MT-2 & AAL87687 & $6 e-12$ & KIIG9.6 \\
\hline $\mathrm{AC} 00193 . \mathrm{cl}$ & 31 & 7 & 0 & 24 & Pisum sativum putative senescence-associated protein & BAB3342I & $2 e-61$ & $\mathrm{~F} 58 \mathrm{HI} .7$ \\
\hline AC0093I.cl & 29 & 6 & 0 & 23 & novel & - & - & - \\
\hline AC00079.cl & 28 & 25 & 2 & 1 & Ostertagia ostertagi unknown protein & AAC08432 & $8 e-06$ & - \\
\hline AC00980.cl & 27 & 11 & 0 & 16 & C. elegans Glycerol kinase & AAA79749 & $8 e-70$ & RIIF4.Ib \\
\hline AC0097I.cl & 26 & 9 & 0 & 17 & C. elegans rpl-I Ribosomal Protein Large subunit & NP_49106I & $5 e-116$ & Y7IF9AL. I 3ab \\
\hline ACO1023.cl & 25 & 22 & 2 & 1 & Ostertagia ostertagi putative ES protein F7 & CAD20464 & $9 e-87$ & F02A9.2 \\
\hline $\mathrm{AC} 00913 . \mathrm{cl}$ & 25 & 6 & 17 & 2 & C. elegans ribosomal protein L37 & O62388 & $2 e-50$ & WOID2. Ib \\
\hline AC02930.cl & 24 & 0 & 0 & 24 & C. elegans calponin-like protein & NP_5047I2 & $4 e-119$ & $\mathrm{~T} 25 \mathrm{~F} 10.6^{\mathrm{b}}$ \\
\hline AC00252.cl & 24 & 12 & 12 & 0 & C. elegans rpl-43 & CAB54440 & $4 e-49$ & Y48B6A. $2^{b}$ \\
\hline $\mathrm{ACO} 1020 . \mathrm{cl}$ & 23 & 20 & 3 & 0 & C. elegans rps-15 Ribosomal Protein Small subunit RPS-I5 & NP_492384 & $\mathrm{le}-88$ & $\mathrm{~F} 36 \mathrm{~A} 2.6^{\mathrm{b}}$ \\
\hline
\end{tabular}

a SW/TR is Swiss-prot and TrEMBL Proteinknowledgebase http://us.expasy.org/sprot/.

${ }^{b} \mathrm{C}$. elegans homolog has higher probability match than the best GenBank descriptor. 
Table 6: The most abundantly represented transcripts in the $A$. ceylanicum cDNA libraries

\begin{tabular}{|c|c|c|c|c|c|c|c|}
\hline \multirow{3}{*}{ A. ceylanicum cluster id } & \multirow{3}{*}{ ESTs Per cluster } & \multicolumn{5}{|c|}{ non-redundant GenBank } & \multirow{3}{*}{$\begin{array}{l}\text { C. elegans gene } \\
\text { Wormpep } 97 \mathrm{~b}\end{array}$} \\
\hline & & \multicolumn{2}{|c|}{ ESTs from Library } & \multirow[b]{2}{*}{ Best identity descriptor } & \multirow{2}{*}{$\begin{array}{l}\text { Accession } \\
\mathrm{SW} / \mathrm{TR}^{\mathrm{a}}\end{array}$} & \multirow[b]{2}{*}{ E-value } & \\
\hline & & iL3 & Ad & & & & \\
\hline AE00908.cl & 323 & 320 & 3 & C. elegans stress associated endoplasmic reticulum protein & NP_510604 & $9 e-37$ & $\mathrm{~F} 59 \mathrm{~F} 4.2^{\mathrm{b}}$ \\
\hline AE00787.cl & 205 & 205 & 0 & C. elegans hsp- 12.6 alpha-B-crystallin & Q20165 & $7 e-39$ & F38EII.2b \\
\hline AEOII04.cl & 155 & 155 & 0 & C. elegans microsomal signal peptidase $25 \mathrm{kDa}$ subunit & Q9XWWI & $8 e-80$ & Y37D8A.10b \\
\hline AE00463.cl & 119 & 118 & 1 & C. elegans dlc-I dynein light chain (I0.3 kD) & NP_498422 & $9 e-56$ & T26A5.9b \\
\hline AE00I2I.cl & 110 & 0 & 110 & C. elegans vit-3 Vitellogenin 3 precursor & NP_508613 & $7 e-121$ & F59D8. $I^{b}$ \\
\hline AE00890.cl & 84 & 84 & 0 & C. elegans spp-4 SaPosin-like Protein family & NP_509237 & $5 e-16$ & T08A9.8b \\
\hline AE00065.cl & 84 & 84 & 0 & C. elegans putative endoplasmic reticulum protein & NP_508656 & $\mathrm{le}-35$ & F47B7. $\left.\right|^{\mathrm{b}}$ \\
\hline AE00360.cl & 74 & 74 & 0 & novel & - & - & - \\
\hline AE00048.cl & 72 & 72 & 0 & C. elegans rpl-29 60S ribosomal protein L29 & NP_50267I & $6 e-25$ & B05।3.3b \\
\hline AE00003.cl & 70 & 3 & 67 & novel & - & - & - \\
\hline AE0I4I0.cl & 63 & 60 & 3 & Ostertagia ostertagi putative ES protein F7 & CAD20464 & $3 e-86$ & F02A9.2 \\
\hline AE00056.cl & 62 & 56 & 6 & C. elegans hypothetical protein & AAK77617 & $5 e-39$ & $\mathrm{MOIH} 9.3 \mathrm{a}^{\mathrm{b}}$ \\
\hline AE00464.cl & 61 & 61 & 0 & novel & - & - & - \\
\hline AE00227.cl & 59 & 0 & 59 & Zea mays extensin-like protein & S49915 & $2 e-31$ & ZK84.I \\
\hline AE00746.cl & 54 & 0 & 54 & C. elegans protein contains chitin binding peritrophin-A domain & AAAI 9083 & $3 e-54$ & B0280.5b \\
\hline AE00750.cl & 50 & 36 & 14 & C. elegans far-7 fatty Acid/Retinol binding protein & NP_493708 & $7 e-45$ & $\mathrm{KOIA} 2.2 \mathrm{a}^{\mathrm{b}}$ \\
\hline AE00072.cl & 47 & 0 & 47 & Beta vulgaris chitinase & S51939 & $6 e-12$ & C34D4.II \\
\hline AE0059I.cl & 45 & 45 & 0 & C. elegans hypothetical protein & AAF99918 & $7 e-26$ & F29B9.IIb \\
\hline AE0I22I.cl & 44 & 44 & 0 & Volvox carteri hydroxyproline-rich glycoprotein DZ-HRGP & CAB62280 & $1 e-29$ & Y59A8B. 19 \\
\hline AE0I407.cl & 41 & 41 & 0 & C. elegans elt-3 GATA-binding transcription factor like & CAA93510 & $5 e-18$ & K02B9.4b \\
\hline AE00033.cl & 41 & 0 & 41 & Nippostrongylus brasiliensis hsp-20 Nbhsp20 & CAA50655 & $8 e-56$ & T27E4.3 \\
\hline AE0I36I.cl & 40 & 39 & I & C. elegans ICD-I inhibitor of cell death & AAA68776 & $\mathrm{le}-75$ & $\mathrm{C} 56 \mathrm{Cl} 0.8^{\mathrm{b}}$ \\
\hline AE00322.cl & 39 & 37 & 2 & C. elegans hypothetical protein & CAB544I6 & $7 e-28$ & Y38EI0A.24b \\
\hline AE00536.cl & 36 & 34 & 2 & Homo sapiens unnamed protein product & BAB7 1316 & $4 e-134$ & F25B5.4a \\
\hline AE00503.cl & 35 & 13 & 22 & C. elegans eft- 3 elongation factor I-alpha & NP_498520 & $3 e-283$ & F3IE3.5b \\
\hline
\end{tabular}

a SW/TR is Swiss-prot and TrEMBL Proteinknowledgebase http://us.expasy.org/sprot/.

b $C$. elegans homolog has higher probability match than the best GenBank descriptor.

Table 7: C. elegans candidate orphans (1,358 out of 21,437) matching Ancylostoma clusters

\begin{tabular}{|c|c|c|c|c|c|c|c|}
\hline C. elegans gene ${ }^{a}$ & Descriptor & Ancylostoma cluster id & ESTs per cluster & E-value & $\begin{array}{l}\text { C. elegans gene length } \\
\text { (aa) }\end{array}$ & $\begin{array}{l}\text { Matched region length } \\
(\%)\end{array}$ & $\%$ ID \\
\hline F3IE8.I & Hypothetical protein & AC05087.cl & 1 & $\mathrm{le}-07$ & 249 & 14.5 & 45 \\
\hline F57B I0.14 & Hypothetical protein & AE02023.cl & 2 & $3 e-20$ & 56 & 75.0 & 69 \\
\hline \multirow[t]{2}{*}{ RI0E9.3 } & Contains Cytochrome $\mathrm{C}$ heme-binding site & AC02329.cl & 1 & $2 e-10$ & 149 & 79.2 & 32 \\
\hline & & AE00556.cl & 2 & $5 e-19$ & 149 & 97.3 & 31 \\
\hline T07A9.13 & Putative nuclear encoded protein & AE02236.cl & 1 & $4 e-31$ & 111 & 91.9 & 49 \\
\hline Y35H6.I & Hypothetical protein & AE03902.cl & 1 & $6 e-23$ & 161 & 47.2 & 48 \\
\hline Y4IC4A.3 & Hypothetical protein & AE00269.cl & 14 & $\mathrm{le}-05$ & 162 & 49.4 & 37 \\
\hline \multirow[t]{2}{*}{ Y54G2A.27 } & Hypothetical protein & AC04390.cl & 1 & $2 e-05$ & 229 & 14.4 & 38 \\
\hline & & AE01938.cl & 9 & $8 e-07$ & 229 & 11.4 & 48 \\
\hline ZC487.3 & Hypothetical protein & AC04655.cl & 1 & $2 e-08$ & 79 & 81.0 & 38 \\
\hline \multirow[t]{2}{*}{ ZK686.I } & Nuclear transition protein & AC00867.cl & 16 & $2 e-07$ & 44 & 68.2 & 62 \\
\hline & & AE0I65I.cl & 3 & $3 e-07$ & 44 & 68.2 & 62 \\
\hline ZK84.5 & Hypothetical protein & AC004I0.cl & 3 & $6 e-11$ & 84 & 70.2 & 46 \\
\hline
\end{tabular}

a Of 21,437 proteins 1,358 were candidate orphans

b AC, Ancylostoma caninum; AE, A. ceylanicum

to the parasites at various stages. Differences in gene expression between A. ceylanicum stages have been demonstrated previously for several genes $[27,28]$. Our comparison of iL3 and adult suggests additional examples (see Discussion). In fact, only $9 \%$ of the A. ceylanicum clusters are shared between iL3 and adult (Figure 2) and of the 25 largest clusters, 23 were biased toward one of the developmental stages (Table 6). While representation in EST collections generally correlates with source expression level [29], artifacts can occur [30,31]. Differences in expression are most likely to be accurate when comparing the most abundant transcripts in each stage. Therefore, while follow-up work is needed to confirm expression lev- 
els, examination of ESTs provides a list of candidates for various expression profiles.

\section{Discussion \\ Overview}

We have taken a genomics approach to the study of hookworm species, key parasites of humans and domestic animals that are related to the model nematode Caenorhabditis elegans. Nearly 20,000 ESTs from Ancylostoma caninum and A. ceylanicum identified approximately 7,000 genes including over 1,300 likely orthologs represented in both species. Close to 900 genes encode putative enzymes involved in 88 metabolic pathways. Over 3,100 genes contain recognizable protein domains many of which have been categorized in the Gene Ontology hierarchy. 4,600 genes have homologs in C. elegans including numerous nematode-specific genes and hundreds with observable RNAi phenotypes. ESTs originated from libraries representing infective L3 larva, stimulated L3, tissue arrested L3, and adults resulting in an improved rate of gene discovery and allowing the identification of transcripts abundant in various stages.

\section{Gene expression in iL3 and dauers}

Infective L3 (iL3) are developmentally-arrested, non-feeding pre-parasitic stages, which when triggered by the infection process and host-specific signals reactivate, molt and complete development. A similar stage in C. elegans is called the dauer larva. In Ancylostoma species host factors such as dog serum stimulate feeding and an activation response in serum stimulated L3 (ssL3) [32] that approximates the transition to parasitism in the host [33]. A. caninum tissue-arrested L3 (taL3) recovered from infected mice are a distinct population that potentially share properties with the arrested iL3. Developmentally arrested, non-feeding larvae would be expected to be dependent on stored energy reserves and lipid metabolic pathways; accordingly, the KEGG biochemical pathway mappings show a substantive number of clusters for fatty acid metabolism especially with the A. ceylanicum iL3 clusters (Table 4).

C. elegans microarray experiments identified 540 dauerenriched genes along with genes involved in dauer-recovery [34]. C. elegans SAGE experiments identified 358 candidate dauer-specific genes [35]. Genes shown to be abundantly expressed in C. elegans dauers include a variety of genes that may play roles in extended survival including heat shock protein encoding genes like hsp-12.6 and daf-21 (Hsp90), ctl-1 (cytosolic catalase), sod-3 (superoxide dismutase), and hil-1 and hil-3 (Histone $\mathrm{H} 1$ 's). A number of genes identified both in Ancylostoma L3s and C. elegans dauers are discussed below.

\section{Heat-shock Proteins}

hsp-12.6, a member of the hsp-20 family, was one of the most highly represented clusters in A. caninum iL3 and taL3 as well as A. ceylanicum iL3 (Table 5 and Table 6). Among a Strongyloides stercoralis EST collection, the gene is also found in iL3 but not L1 [17]. C. elegans hsp-12.6 is upregulated in dauer and starved L1s $[34,36]$ and is a transcriptional target of the FOXO transcription factor DAF-16 [37]. Unlike other HSPs, C. elegans hsp-12.6 is not stressinduced and does not prevent aggregation of unfolded proteins, suggesting a novel role. AE00033.cl, found exclusively in adult ESTs, encodes an ortholog of the Nippostrongylus brasiliensis HSP-20 protein. $N b$ - $h s p-20$ is more similar to the HSP-16 group of the HSP-20 family of small HSPs in C. elegans, is also expressed in the adult [38], and is not stress regulated, suggesting that it may function as an adult version of $h s p-12.6$.

\section{Candidate stress-response proteins}

A. caninum iL3 showed abundant clusters encoding homologs of the mitochondrial cytochrome oxidase subunits I, II, III and a stress associated endoplasmic reticulum protein not seen in ssL3 (Table 5). One A. ceylanicum iL3 abundant cluster encoded a ribosome-associated membrane 4 protein (RAMP4) involved in ER protein translocation [39] which is over-expressed in hypoxia and suppresses degradation of ER membrane proteins [40]. A homolog of C. elegans spp-4 was also expressed at high levels in A. ceylanicum iL3. spp-4 encodes an amoebapore, a member of the saposin-like protein superfamily that kill bacteria by forming membrane ion channels [41]. Amoebapore proteins are one of a number of putative stress response proteins regulated by DAF-16 in C. elegans $[37,42]$. These proteins, also including lysozyme and thaumatin, may provide a defense against worm pathogens and contribute to dauer longevity [43]. Hookworm free-living stages are also soil dwelling microbiverous organisms exposed to soil pathogens, so it is possible that spp-4 plays an antibacterial role in A. ceylanicum.

\section{Gene expression in ssL3, adults, and multiple stages}

In contrast to iL3, A. caninum ssL3 showed a CMP-sialic acid transporter, cathepsin D-like aspartic protease, calponin-like protein, and ham-2 zinc finger protein among the abundant transcripts. While the significance of these molecules is unknown, upregulation of an aspartic protease during the transition to parasitism and tissue penetration/migration is consistent with its role in degradation of serum proteins and collagens [44].

Abundant adult-specific clusters are likely to be involved in reproduction. For example, A. ceylanicum (Table 6) encodes an ortholog of the C. elegans VIT-3 protein, a lipid binding protein and major yolk component [45]. VIT-3 is expressed exclusively in the $C$. elegans adult 
hermaphrodite intestine, secreted, and taken up by oocytes. Two clusters encode genes involved in metabolism of chitin, an important constituent of the nematode eggshell [46]. One encodes a protein similar to C. elegans protein C34D4.11, and shows some similarity to a beet chitinase; the other encodes an ortholog of C. elegans B0280.5, a protein required for early embryonic development [47]. B0280.5 mRNA is expressed specifically in the adult hermaphrodite germ line and is a target of GLD-1, an RNA binding protein required for oocyte meiotic cell cycle progression [48].

\section{ASP's}

While there are differences in the cluster profiles among Ancylostoma stages, there are shared transcripts as well. For example, the Ancylostoma secreted protein ASP-1 and ASPlike cDNAs are present in abundance in both A. caninum iL3 and ssL3. The secretion of ASP-1 protein by ssL3s was noted as a marker of the transition to parasitism [12]. These results support conclusions made by Wang and Kim [34] that arrested larvae are transcriptionally prepared for dauer exit and upon receipt of appropriate stimulatory signals, exit from the arrested state is accompanied by a burst of translational activity in addition to further transcriptional activity. In contrast to ASP-1, ESTs for ASP-2 were exclusively detected in A. caninum iL3.

\section{FAR Proteins}

Two of the most abundant A. ceylanicum transcripts encode fatty acid/retinol binding (FAR) proteins (Table 6). FAR proteins are novel fatty acid and retinol binding proteins described in nematodes including A. caninum, other Strongylida, filarial, and plant parasitic species [4951]. In C. elegans 8 FAR members are divided into 3 groups. All the parasitic nematodes FARs described to date are most similar to the $C$. elegans A group containing $\mathrm{Ce}$ far-1, -2, and -6. Seven A. ceylanicum clusters encode FAR proteins. Four of which (9 ESTs) were found in the adult cDNA library; clusters AE00748.cl and AE03203.cl were nearly identical to Ac-far-1 and Ac-far-2 (98\% and 99\% nucleotide identity) whereas cluster AE02490.cl showed the highest similarity to Ce-far-1 and AE01700.cl to Ac-far2. The iL3 specific clusters AE01410.cl (60/63 ESTs from iL3) and AE03983.cl (2/2 ESTs from iL3) were both most closely related to a FAR protein from Ostertagia ostertagi [52], and more distantly to Ac-far-1 and -2. Therefore, as seen in other parasitic nematodes, most $A$. ceylanicum FAR proteins are related to $C$. elegans group A FAR proteins. However, the A. ceylanicum cluster AE00750 was most similar to group C FAR protein Ce-far-7. Group C proteins differ from the other FARs in important ways including lacking an N-terminal signal peptide (suggesting an intracellular location), containing several cysteines, and failing to bind DAUDA [53]. AE00750.cl represents the first report of a FAR-7 like protein from a parasitic nematode.
The function of FAR proteins is unknown but may represent a lipid acquisition system in which released FARs bind to lipids followed by uptake of the complex by a specific receptor mediated process. Retinoids are required for nematode growth and development, but are not synthesized by the worms. In parasitic nematodes, release of FAR proteins may also modify local inflammatory and immunological responses by delivering or sequestering biochemically important lipids [54].

\section{Conclusion}

The application of genomic approaches to hookworms has resulted in more than a 100-fold increase in available sequence data from Ancylostoma species thereby allowing an initial bioinformatic analysis of transcripts from these important parasites and establishing a foundation for the eventual completion of a hookworm genome. Semi-automated informatic approaches that are now being applied to all nematode sequences [55] allow uniform comparisons across many genomes and provide databases for further exploration. Transcripts in A. caninum and A. ceylanicum include clear candidates for stage specific expression representing the very different biological processes underway in different points of the lifecycle. The availability of the C. elegans and C. briggsae genomes has allowed highly informative comparisons to the two hookworm species showing extensive overlap in gene complements, including genes demonstrated to be essential in C. elegans and numerous genes specific to nematodes. As the most closely related major human pathogen to C. elegans, hookworms provide an attractive near-term application for using a model organism to better understand and eventually control a key disease-causing species. Beyond categorization of hookworm genes, clear research avenues are available to apply this information to improved methods for hookworm control including anthelmintic and vaccine development, diagnostics, population studies, as well as better understanding of fundamental aspects of hookworm biology, such as host immune system modulation.

\section{Methods \\ Nematode extraction}

A Shanghai strain of A. caninum was maintained in beagles as described [56]. Infective L3 (iL3) were recovered from 7-10 day old coprocultures using a modified Baermann technique, washed clean of debris with $\mathrm{BU}$ buffer $\left(50 \mathrm{mM} \mathrm{Na} 2 \mathrm{PO}_{4} / 22 \mathrm{mM} \mathrm{KH}{ }_{2} \mathrm{PO}_{4} / 70 \mathrm{mM} \mathrm{NaCl}\right.$, pH $6.8 ;[57])$, and snap-frozen by immersion in liquid $\mathrm{N}_{2}$. Frozen larvae were stored at $-80^{\circ} \mathrm{C}$ until used for library construction. Serum stimulated larvae (ssL3) were generated by incubating iL3s harvested from a North Carolina strain of A. caninum in 5\% normal dog serum for $20-24 \mathrm{~h}$ at $37^{\circ} \mathrm{C}, 5 \%$ carbon dioxide. Tissue-arrested L3 larvae (taL3) were recovered from BALB/c mice infected with 
1,000-1,500 iL3 (North Carolina strain) and euthanized at 10-14 days post-infection [58].

A Warsaw strain of A. ceylanicum was maintained in Syrian hamsters as described [59], and $\mathrm{L}_{3}$ recovered, washed, and frozen as above. For the recovery of adult stage A. ceylanicum, infected hamsters with patent infections were sacrificed and the small intestine removed. The intestine was cut into 3 sections, opened longitudinally, and hung in 50 $\mathrm{ml}$ centrifuge tubes containing phosphate buffered saline at $37^{\circ} \mathrm{C}$ for $2-3 \mathrm{hrs}$. Following incubation, adult worms were recovered from the sediment, washed free of debris, and snap-frozen as above. All animals were housed and treated in accordance with institutional care and use committee guidelines.

\section{Preparation of A. caninum staged RNA and CDNA libraries}

Pulverization for the ssL3 and taL3 was performed using an Alloy Tool Steel Set (Fisher Scientific International). Total RNA from adult and larval parasites was prepared using TRIzol Reagent (GibcoBRL, Life Technologies or Invitrogen, Carlsbad, CA).

SMART based serum stimulated L3 library - Library construction was based on the SMART cDNA library construction system (Clontech Laboratories; [60]). mRNA was extracted from $10 \mu \mathrm{g}$ of total RNA using a Dynabeads mRNA Purification kit (Dynal Biotech) with some modifications. First strand synthesis was performed with the mRNA bound to the oligo-dT of the Dynabeads using Superscript II RT (Invitrogen, Life Technologies) and the primer smart T7_3G_5. Concatemers were digested with Not I on the bead. Second strand synthesis was performed with the smartT7_5 and the smartCDSII primer. Amplification of the CDNA was performed with the smartT7_5 and smartT7_3 primers with cycling parameters of $95^{\circ} \mathrm{C}$ for 5 minutes, seven cycles of $95^{\circ} \mathrm{C}$ for 5 seconds, $60^{\circ} \mathrm{C}$ for 5 seconds and $68^{\circ} \mathrm{C}$ for 6 minutes followed by a 4 minute extension at $68^{\circ} \mathrm{C}$. Following amplification, the cDNA was purified using the High Pure PCR Product Purification Kit (Roche). The final 5 cycles of PCR introduced the deoxy-UMP primers needed for cloning into the pAMP1 vector (Invitrogen, Life Technologies). cDNA fragments $>1 \mathrm{~kb}$ were size selected on a $0.8 \%$ TAE agarose gel and cloned into the pAMP1 vector following the CloneAMP pAMP1 System (Invitrogen, Life Technologies). The ligation mix introduced into E. coli DH10B chemically competent cells (GibcoBRL, Life Technologies) resulted in $4.36 \times 10^{5}$ primary transformants.

SL1-PCR-based tissue arrested L3 library - mRNA was extracted from $2 \mu \mathrm{g}$ of total RNA using a Dynabeads mRNA Purification kit (Dynal Biotech) and eluted with $10 \mu \mathrm{l} 10 \mathrm{mM}$ Tris-HCl. First strand synthesis was per- formed using linker primer (GAGAGAGAGAGAGAGAGAGAACTAGTCTCGAGTTTTTTTTTTTTT) and Superscript II RT (Invitrogen, Life Technologies). Amplification with Taq Polymerase used the SL1 (GGGTTTAATTACCCAAGTTTGA) and Xhop (GAGAGAGAACTAGTCTCGA) primers and $5 \mu \mathrm{l}$ of the first strand reaction. Cycling parameters were $95^{\circ} \mathrm{C}$ for 5 minutes, 30 cycles of $95^{\circ} \mathrm{C}$ for 1 minute, $47^{\circ} \mathrm{C}$ for 1 minute, $72^{\circ} \mathrm{C}$ for 3 minutes followed by 5 minutes at $72^{\circ} \mathrm{C}$. cDNA fragments $>1 \mathrm{~kb}$ were size selected on a $0.8 \%$ TAE agarose gel and cloned into the pCRII-TOPO vector following the TOPO TA protocol (Invitrogen). The ligation mix was introduced into E. coli DH1OB chemically competent cells (GibcoBRL, Life Technologies).

Hawdon infective $\mathrm{L}_{3}$ library - Frozen A. caninum L3 pellets were ground to powder on a mortar pre-chilled with liquid nitrogen. Total RNA was isolated from the powder using Trizol reagent (Invitrogen, Carlsbad, CA). Poly (A)+ RNA was isolated from total RNA using the Oligotex mRNA isolation kit (Qiagen, Chatsworth, CA). Approximately $5 \mu \mathrm{g}$ of mRNA was used to construct a directional cDNA library in Lambda ZAP II (Stratagene, La Jolla, CA) as previously described [61]. pBluescript phagemid were mass excised prior to sequencing. The library had $>95 \%$ recombinants, and insert size varied from 700-3,000 bp. The library was amplified once $\left(10^{6} \mathrm{pfu}\right)$.

\section{Preparation of A. ceylanicum staged RNA and CDNA libraries}

Hawdon adult and infective L3 A. ceylanicum libraries Total RNA and poly (A)+ mRNA were isolated from the appropriate A. ceylanicum life-cycle stage using Trizol reagent and the Oligotex mRNA isolation kit as described above. Approximately $5 \mu \mathrm{g}$ of mRNA was used to construct directional cDNA libraries in Lambda ZAP II (Stratagene, La Jolla, CA) as previously described [61]. Both libraries had 99\% recombinants with inserts ranging from 500-2500 bp (average $1500 \mathrm{bp}$ ), and each underwent one round of amplification $\left(10^{6} \mathrm{pfu}\right)$. Inserts were mass excised as described above.

SL1-PCR-based infective L3 and adult libraries - cDNA was PCR amplified, using SL1-EcoRI primer on the $5^{\prime}$ end and oligo(dT)-Xhol on 3' end, gel fractionated [62], and non-directionally cloned into pCR-TOPO-XL (Invitrogen), following XL-Topo TA cloning protocol. The cDNA inserts were excised with EcoRI.

\section{Sequencing and clustering}

Sequencing, EST processing and clustering were performed as described [17]. Information for clone requests and sequence trace files are available at http://www.nem atode.net. The completed cluster assemblies, NemaGene Ancylostoma caninum $\mathrm{v} 2.0$ and A. ceylanicum v 2.0, were 
used as the basis for all subsequent analyses and are available for searching and acquisition by FTP at http:// www.nematode.net. "Fragmentation", defined as the representation of a single gene by multiple non-overlapping clusters, was estimated by examining Ancylostoma clusters with homology to C. elegans [17]. Overall representation of Ancylostoma genes is based on a theoretical gene number of 21,437, comparable to C. elegans wormpep97.

\section{Analysis and functional assignments}

Homology assignments - WU-BLAST sequence comparisons $[63,64]$ were performed using $A$. caninum and $A$. ceylanicum contig consensus sequences which were further organized into clusters. Consensus sequences were used to search multiple databases, including the non-redundant GenBank (3/20/2003) and Wormpep v.97 C. elegans (Wellcome Trust Sanger Institute, unpublished) protein databases. Internally constructed databases using intersections of data from Genbank, allowed examination of sequences in specific phylogenetic distributions. Homologies were reported for $\mathrm{E}$ (expect) value scores of $\geq 1 \mathrm{e}-05$.

To identify cases where Ancylostoma homologs in C. elegans have been surveyed for knock-down phenotypes using RNA interference, Wormpep BLAST matches were cross-referenced to a list of 17,042 C. elegans genes with available RNAi information (20 th February 2005) http:// www.wormbase.org. For each Ancylostoma cluster, only the best C. elegans match was considered.

Functional classification - Clusters were assigned putative functional categorization using two methods. First, InterProScan v.3.1 ftp://ftp.ebi.ac.uk/pub/software/unix/ iprscan was used to search contig translations versus InterPro domains (11/08/02) [65,66]. Using InterPro, clusters were mapped to the three organizing principles of the Gene Ontology (GO_200211_assocdb.sql) [67]. Mappings are stored by MySQL database, displayed using AmiGo (11/25/02) http://www.godatabase.org/cgi-bin/ go.cgi, and are available at http://www.nematode.net. Second, clusters were assigned by enzyme commission number to metabolic pathways using the Kyoto Encyclopedia of Genes and Genomes (KEGG) database $(2 / 24 / 2004)[68$ ]. All matches better than 1e-10 were taken into consideration.

Orthologs and dN/dS ratio - A. caninum / A. ceylanicum orthologs were determined by reciprocal best TBLASTX match using a threshold of $E$ value $\geq 10^{-5}$. In addition, the ORFs accepted to be the correct translation were required to have the best $C$. elegans gene match in the same frame as the TBLASTX matches. Only continuous alignments longer than 30 amino acids were accepted. 'Suboptimal alignment program' (Jason Stajich, unpublished), scripted using tools in Bioperl [69] and utilizing 'yn00' from PAML [70], calculated the synonymous (dS) and non-synonymous substitutions $(\mathrm{dN})$ per ortholog pair. A 4 -way orthologs were assigned by using SSEARCH [71,72] to find the best $C$. elegans and C. briggsae homolog for each ortholog pair of $A$. caninum and A. ceylanicum. Orthologs were assigned if both sequences agreed on the best hits. Multiple sequence alignments were performed with MUSCLE [73]. Trees were built using the programs 'protml' and 'nucml' for protein and nucleotide sequences respectively [26]. An exhaustive search was used first to enumerate the possible topologies and then - $\mathrm{R}$ rearrangement search was used to identify the most likely branch lengths and bootstrap values. Only genes for which well supported topologies where A. caninum and A. ceylanicum appeared as sisters were used in subsequent analysis. Tree branch lengths were parsed and processed with Perl scripts written using modules from the Bioperl package and statistical tests were applied with the R package [74].

\section{List of abbreviations used}

Ad, adult parasite stage; BLAST, basic local alignment search tool; dN, non-synonymous substitutions; dS, synonymous substitutions; EST, expression sequence tag; GO, gene ontology; iL3, infective third larval stage; KEGG, Kyoto encyclopedia of genes and genomes; PCR, polymerase chain reaction; ssL3, serum-stimulated L3; taL3, tissuearrested L3.

\section{Authors' contributions}

MM, JPM, SWC, RKW, and RHW conceived and designed the research plan and participated in all aspects of data collection and analysis. MM, JPM, MD, TW, JX, and JES analyzed and interpreted the data. $\mathrm{PA}, \mathrm{JH}$, and WK contributed material and constructed cDNA libraries. MM, JPM, PA, and JH drafted the manuscript. All authors read and approved the final manuscript.

\section{Additional material}

Additional File 1
Accession numbers.
Click here for file
[http://www.biomedcentral.com/content/supplementary/1471-
2164-6-58-S1.doc]

Additional File 2

Most conserved nematode genes between A. caninum and C. elegans. Click here for file

[http://www.biomedcentral.com/content/supplementary/14712164-6-58-S2.xls]

\section{Additional File 3}

Classification of C. elegans RNAi phenotypes for genes with A. caninum and A. ceylanicum homologs.

Click here for file

[http://www.biomedcentral.com/content/supplementary/1471-

2164-6-58-S3.xls] 


\section{Additional File 4}

C. briggsae candidate orphans matching Ancylostoma clusters. Click here for file

[http://www.biomedcentral.com/content/supplementary/14712164-6-58-S4.xls]

\section{Acknowledgements}

Ancylostoma EST sequencing at Washington University was supported by NIH-NIAID research grant Al 46593 to RHW. The authors would like to thank B. Chiapelli, C. Murphy, D. Pape, Bin Zhan, Adriana Magalska and E. Janecka for technical assistance, Reshad Dobardzic, Halina Wedrychowicz and Jerzy Behnke, for providing larval strains, and Peter Hotez and the Human Hookworm Initiative from the Sabin Vaccine Institute for their support. JPM was supported by a Helen Hay Whitney/Merck Fellowship. JES is supported by an NSF pre-doctoral fellowship. JPM is employee and equity holder of Divergence Inc; this research was not company funded.

\section{References}

I. de Silva NR, Brooker S, Hotez PJ, Montresor A, Engels D, Savioli L: Soil-transmitted helminth infections: updating the global picture. Trends Parasitol 2003, I 2:547-55I.

2. Anderson RC: Nematode Parasites of Vertebrates, Their Development and Transmission New York: CABI Publishing; 2000.

3. Schad GA: Hypobiosis and related phenomena in hookworm infection. In Hookworm Disease Current Status and New Directions Edited by: Schad GA, Warren KS. London: Taylor and Francis; 1990:7I-88.

4. Stone WM, Girardeau MR: Transmammary passage of Ancylostoma caninum larvae in dogs. J Parasitol 1968, 54:426-429.

5. Arasu P: Anthelmintic efficacy against tissue-arrested larvae of Ancylostoma caninum in murine hosts. J Parasitol 1998, 84: $1263-1267$

6. Hotez PJ, Zhan B, Bethony JM, Loukas A, Williamson A, Goud GN, Hawdon JM, Dobardzic A, Dobardzic R, Ghosh K, et al.: Progress in the development of a recombinant vaccine for human hookworm disease: the Human Hookworm Vaccine Initiative. Int J Parasitol 2003, 33:1245-1258.

7. Boguski MS, Tolstoshev CM, Bassett DE): Gene discovery in dbEST. Science 1994, 265:1993-1994.

8. Blaxter ML, De Ley P, Garey JR, Liu LX, Scheldeman P, Vierstraete A, Vanfleteren JR, Mackey LY, Dorris M, Frisse LM, et al.: A molecular evolutionary framework for the phylum Nematoda. Nature 1998, 392:7|-75.

9. Blaxter M: Genes and genomes of Necator americanus and related hookworms. Int J Parasitol 2000, 30:347-355.

10. The C.elegans Sequencing Consortium: Genome Sequence of the Nematode C. elegans: A Platform for Investigating Biology. Science 1998, 282:2012-2018.

II. Daub J, Loukas A, Pritchard DI, Blaxter M: A survey of genes expressed in adults of the human hookworm, Necator americanus. Parasitology 2000, I 20: I7I-I84.

12. Hawdon JM, Jones BF, Hoffman DR, Hotez PJ: Cloning and characterization of Ancylostoma-secreted protein. A novel protein associated with the transition to parasitism by infective hookworm larvae. J Biol Chem 1996, 27I:6672-6678.

13. Gasser RB, Newton SE: Genomic and genetic research on bursate nematodes: significance, implications and prospects. Int J Parasitol 2000, 30:509-534.

14. Hoekstra R, Visser A, Otsen M, Tibben J, Lenstra JA, Roos MH: EST sequencing of the parasitic nematode Haemonchus contortus suggests a shift in gene expression during transition to the parasitic stages. Mol Biochem Parasitol 2000, I 1 0:53-68.

15. Jasmer DP, Dautova Mitreva M, McCarter IP: mRNA sequences for Haemonchus contortus intestinal cathepsin B-like cysteine proteases display an extreme in abundance and diversity compared with other adult mammalian parasitic nematodes. Mol Biochem Parasitol 2004, 137:297-305.
16. Harcus YM, Parkinson J, Fernandez C, Daub J, Selkirk ME, ML B, Maizels RM: Signal sequence analysis of expressed sequence tags from the nematode Nippostrongylus brasiliensis and the evolution of secreted proteins in parasites. Genome Biol 2004, 5:R39.

17. Mitreva M, McCarter JP, Martin J, Dante M, Wylie T, Chiapelli B, Pape D, Clifton SW, Nutman TB, Waterston RH: Comparative Genomics of Gene Expression in the Parasitic and Free-living Nematodes Strongyloides stercoralis and Caenorhabditis elegans. Genome Res 2004, I 4:209-220.

18. Stein LD, Bao Z, Blasiar D, Blumenthal T, Brent MR, Chen N, Chinwalla A, Clarke L, Clee C, Coghlan A, et al.: The Genome Sequence of Caenorhabditis briggsae: A Platform for Comparative Genomics. PLoS Biol 2003, I:E45.

19. Bin Z, Hawdon J, Qiang S, Hainan R, Huiqing Q, Wei H, Shu-Hua X, Tiehua L, Xing G, Zheng F, Hotez P: Ancylostoma secreted protein I (ASP-I) homologues in human hookworms. Mol Biochem Parasitol 1999, 98:143-149.

20. Hotez PJ, Hawdon JM, Cappello M, Jones BF, Pritchard DI: Molecular pathobiology of hookworm infection. Infect Agents Dis 1995, 4:71-75.

21. Tawe W, Pearlman E, Unnasch TR, Lustigman S: Angiogenic activity of Onchocerca volvulus recombinant proteins similar to vespid venom antigen 5. Mol Biochem Parasitol 2000, 109:91-99.

22. Ding X, Shields J, Allen R, Hussey RS: Molecular cloning and characterisation of a venom allergen AG5-like cDNA from Meloidogyne incognita. Int J Parasitol 200I, 30:77-8I.

23. Zhan B, Badamchian M, Meihua B, Ashcom J, Feng J, Hawdon J, Shuhua $X$, Hotez PJ: Molecular cloning and purification of Ac-TMP, a developmentally regulated putative tissue inhibitor of metalloprotease released in relative abundance by adult Ancylostoma hookworms. Am J Trop Med Hyg 2002, 66:238-244.

24. Waterston RH, Lindblad-Toh K, Birney E, Rogers J, Abril JF, Agarwal P, Agarwala R, Ainscough R, Alexandersson M, An P, et al.: Initial sequencing and comparative analysis of the mouse genome. Nature 2002, 420:520-562.

25. Kamath RS, Fraser AG, Dong Y, Poulin G, Durbin R, Gotta M, Kanapin A, Le Bot N, Moreno S, Sohrmann M, et al: Systematic functional analysis of the Caenorhabditis elegans genome using RNAi. Nature 2003, 421:231-237.

26. Adachi J, Hasegawa M: MOLPHY version 2.3: Programs for Molecular Phylogenetics based on Maximum Likelihood Tokyo: Institute of Statistical Mathematics; 1996.

27. Hawdon JM, Narasimhan S, Hotez PJ: Ancylostoma secreted protein 2: cloning and characterization of a second member of a family of nematode secreted proteins from Ancylostoma caninum. Mol Biochem Parasitol 1999, 99:149-165.

28. Zhan B, Hotez PJ, Wang Y, Hawdon JM: A developmentally regulated metalloprotease secreted by host-stimulated Ancylostoma caninum third-stage infective larvae is a member of the astacin family of proteases. Mol Biochem Parasitol 2002, I 20:29|-296.

29. Audic S, Claverie JM: The Significance of Digital Gene Expression Profiles. Genome Res 1997, 7:986-995.

30. Mitreva M, Jasmer DP, Appleton J, Martin J, Dante M, Wylie T, Clifton SW, Waterston RH, McCarter JP: Gene discovery in the adenophorean nematode Trichinella spiralis: an analysis of transcription from three life cycle stages. Mol Biochem Parasitol 2004, | 37:277-29|

31. Munoz ET, Bogarad LD, Deem MW: Microarray and EST database estimates of mRNA expression levels differ: the protein length versus expression curve for $C$. elegans. BMC Genomics 2004, 5:30.

32. Arasu P, Kwak D: Developmental arrest and pregnancyinduced transmammary transmission of Ancylostoma caninum larvae in the murine model. J Parasitol 1999, 85:779-784.

33. Brand A, Hawdon JM: Phosphoinositide-3-OH-kinase inhibitor LY294002 prevents activation of Ancylostoma caninum and Ancylostoma ceylanicum third-stage infective larvae. Int Parasitol 2004, 34:909-9|4.

34. Wang J, Kim SK: Global analysis of dauer gene expression in Caenorhabditis elegans. Development 2003, I30:162I-1634.

35. Jones SJ, Riddle DL, Pouzyrev AT, Velculescu VE, Hillier L, Eddy SR, Stricklin SL, Baillie DL, Waterston R, Marra MA: Changes in Gene Expression Associated with Developmental Arrest and Lon- 
gevity in Caenorhabditis elegans. Genome Res 200I, I I:1346-1352.

36. Leroux MR, Ma BJ, Batelier G, Melki R, Candido EP: Unique structural features of a novel class of small heat shock proteins. Biol Chem 1997, 272: I 2847-I 2853.

37. Murphy CT, McCarroll SA, Bargmann $\mathrm{Cl}$, Fraser A, Kamath RS, Ahringer J, Li H, Kenyon C: Genes that act downstream of DAF16 to influence the lifespan of Caenorhabditis elegans. [see comment]. Nature 2003, 424:277-283.

38. Tweedie S, Grigg ME, Ingram L, Selkirk ME: The expression of a small heat shock protein homologue is developmentally regulated in Nippostrongylus brasiliensis. Mol Biochem Parasitol I993, 6I:I49-I53.

39. Yamaguchi A, Hori O, Stern DM, Hartmann E, Ogawa S, Tohyama M: Stress-associated endoplasmic reticulum protein I (SERPI) Ribosome-associated membrane protein 4 (RAMP4) stabilizes membrane proteins during stress and facilitates subsequent glycosylation. / Cell Biol 1999, I 47: I I95- I 204.

40. Wang L, Dobberstein B: Oligomeric complexes involved in translocation of proteins across the membrane of the endoplasmic reticulum. FEBS Letters 1999, 457:316-322.

41. Leippe M, Andra J, Nickel R, Tannich E, Muller-Eberhard HJ: Amoebapores, a family of membranolytic peptides from cytoplasmic granules of Entamoeba histolytica: isolation, primary structure, and pore formation in bacterial cytoplasmic membranes. Mol Microbiol 1994, I 4:895-904.

42. Nicholas HR, Hodgkin J: Responses to infection and possible recognition strategies in the innate immune system of Caenorhabditis elegans. Mol Immunology 2004, 41:479-493.

43. Garsin DA, Villanueva JM, Begun J, Kim DH, Sifri CD, Calderwood SB, Ruvkun G, Ausubel FM: Long-lived C.elegans daf-2 mutants are resistant to bacterial pathogens. Science 2003, 300:1921.

44. Williamson AL, Brindley PJ, Loukas A: Hookworm cathepsin D aspartic proteases: contributing roles in the host-specific degradation of serum proteins and skin macromolecules. Parasitology 2003, I 26: 179-185

45. Spieth J, Blumenthal T: The Caenorhabditis elegans vitellogenin gene family includes a gene encoding a distantly related protein. Mol Cellular Biology 1985, 5:2495-250I.

46. Spindler KD, Spindler-Barth M, Londershausen M: Chitin metabolism: a target for drugs against parasites. Parasitol Res 1990, 76:283-288.

47. Lee MH, Schedl T: Identification of in vivo mRNA targets of GLD-I, a maxi-KH motif containing protein required for $C$. elegans germ cell development. Genes Dev 200 I, I5:2408-2420.

48. Hansen D, Wilson-Berry L, Dang T, Schedl T: Control of the proliferation versus meiotic development decision in the $C$. elegans germline through regulation of GLD-I protein accumulation. Development 2004, I $31: 93-104$.

49. Basavaraju S, Zhan B, Kennedy MW, Liu Y, Hawdon J, Hotez PJ: AcFAR-I, a $20 \mathrm{kDa}$ fatty acid- and retinol-binding protein secreted by adult Ancylostoma caninum hookworms: gene transcription pattern, ligand binding properties and structural characterisation. Mol Biochem Parasitol 2003, I 26:63-7I.

50. Garofalo A, Klager SL, Rowlinson MC, Nirmalan N, Klion A, Allen JE, Kennedy MW, Bradley JE: The FAR proteins of filarial nematodes: secretion, glycosylation and lipid binding characteristics. Mol Biochem Parasitol 2002, I 22:161-170.

5I. Prior A, Jones JT, Blok VC, Beauchamp J, McDermott L, Cooper A, Kennedy MW: A surface-associated retinol- and fatty acidbinding protein (Gp-FAR-I) from the potato cyst nematode Globodera pallida: lipid binding activities, structural analysis and expression pattern. Biochem J 200I, 356:387-394.

52. Vercauteren I, Geldhof P, Peelaers I, Claerebout E, Berx G, Vercruysse J: Identification of excretory-secretory products of larval and adult Ostertagia ostertagi by immunoscreening of cDNA libraries. Mol Biochem Parasitol 2003, I 26:201-208.

53. Garofalo A, Rowlinson MC, Amambua NA, Hughes JM, Kelly SM, Price NC, Cooper A, Watson DG, Kennedy MW, Bradley JE: The FAR protein family of the nematode Caenorhabditis elegans. Differential lipid binding properties, structural characteristics, and developmental regulation. I Biol Chem 2003, 278:8065-8074.

54. Bradley JE, Nirmalan N, Klager SL, Faulkner H, Kennedy MW: River blindness: a role for parasite retinoid-binding proteins in the generation of pathology? Trends Parasitol 200 I, I 7:47| I-475.
55. Parkinson J, Mitreva M, Whitton C, Thomson M, Daub J, Martin J, Hall $\mathrm{N}$, Barrell B, Waterston RH, McCarter JP, Blaxter M: A transcriptomic analysis of the phylum Nematoda. Nature Genetics 2004 , 36: |259- I 267.

56. Hawdon JM, Datu BJ: The second messenger cyclic GMP mediates activation in Ancylostoma caninum infective larvae. Int J Parasitol 2003, 33:787-793.

57. Hawdon JM, Schad GA: Long-term storage of hookworm infective larvae in buffered saline solution maintains larval responsiveness to host signals. J Helm Soc Wash |99|, 58:140-142.

58. Arasu P: In vitro reactivation of Ancylostoma caninum tissuearrested third-stage larvae by transforming growth factorbeta. J Parasitol 2001, 87:733-738.

59. Hawdon JM, Volk SW, Pritchard DI, Schad GA: Resumption of feeding in vitro by hookworm third-stage larvae: a comparative study. J Parasitol 1992, 78: 1036-1040

60. Ciavatta V, Cairney J: Isolation of full-length cDNA clones using SMART CDNA and a biotin-streptavidin bead system. Biotechniques 2000, 29:444-446.

6I. Zhan B, Hawdon J, Shan Q, Ren H, Qiang H, Xiao SH, Li TH, Feng Z, Hotez P: Construction and analysis of CDNA library of Necator americanus third stage larvae. J Parasitol Paras Dis 2000, 18:26-28.

62. Osoegawa K, Woon PY, Zhao B, Frengen E, Tateno M, Catanese J], de Jong PJ: An improved approach for construction of bacterial artificial chromosome libraries. Genomics 1998, 15: I-8.

63. Altschul SF, Gish W, Miller W, Myers EW, Lipman DJ: Basic local alignment search tool. J Mol Biol 1990, 21 5:403-410.

64. Gish W: [http://blast.wustl.edu.]. 1996-2002

65. Apweiler R, Attwood TK, Bairoch A, Bateman A, Birney E, Biswas M, Bucher P, Cerutti L, Corpet F, Croning MD, et al.: The InterPro database, an integrated documentation resource for protein families, domains and functional sites. Nucleic Acids Res 200I, 29:37-40

66. Zdobnov EM, Apweiler R: InterProScan - an integration platform for the signature-recognition methods in InterPro. Bioinformatics 200I, 17:847-848.

67. The Gene Ontology Consortium: Gene ontology: tool for the unification of biology. Nat Genet 2000, 25:25-29.

68. Kanehisa M, Goto S: KEGG: kyoto encyclopedia of genes and genomes. Nucleic Acids Res 2000, 28:27-30.

69. Stajich JE, Block D, Boulez K, Brenner SE, Chervitz SA, Dagdigian C, Fuellen G, Gilbert JG, Korf I, Lapp H, et al:: The Bioperl toolkit: Perl modules for the life sciences. Genome Res 2002, I2:1611-1618.

70. Yang Z: PAML: A program package for phylogenetic analysis by maximum likelhood. Comput Appl Biosci 1997, 13:555-556.

71. Pearson WR: Searching protein sequence libraries: comparison of the sensitivity and selectivity of the Smith-Waterman and FASTA algorithms. Genomics |99|, I I:635-650.

72. Smith TF, Waterman MS: Identification of common molecular subsequences. I Mol Biol I 98I, I 47: I 95- I 97.

73. Edgar RC: MUSCLE: multiple sequence alignment with high accuracy and high throughput. Nucleic Acids Res 2004, 32: 1792-I 797.

74. R Development Core team: $R$ : A language and environment for statistical computing. 2004 [http://www.r-project.org/.]

Publish with Bio Med Central and every scientist can read your work free of charge

"BioMed Central will be the most significant development for disseminating the results of biomedical research in our lifetime. "

Sir Paul Nurse, Cancer Research UK

Your research papers will be:

- available free of charge to the entire biomedical community

- peer reviewed and published immediately upon acceptance

- cited in PubMed and archived on PubMed Central

- yours - you keep the copyright
BioMedcentral 